\title{
A Role for Pre-Polymerized Sucralfate in the Management of Erosive and Non-Erosive Gastroesophageal Reflux Disease
}

\author{
Ricky Wayne McCullough, MD, ScM, FAcadTM ${ }^{1,2^{*}}$ \\ ${ }^{1}$ Translational Medicine Clinic and Research Center, Storrs, USA \\ ${ }^{2}$ Department of Internal Medicine and Emergency Medicine, Veterans Administration Medical Center, \\ Warren Alpert Brown University School of Medicine, USA
}

*Corresponding author: Ricky Wayne McCullough MD, ScM, FAcadTM, Translational Medicine Clinic and Research Center, 1768 Storrs Road, Storrs Connecticut, 06268, USA; Department of Internal Medicine and Emergency Medicine, Veterans Administration Medical Center, Warren Alpert Brown University School of Medicine, Rhode Island, 02903, USA

\section{Abstract}

Clinical outcomes from standard sucralfate do not justify role in the management of erosive and non-erosive gastroesophageal reflux disease. Pre-polymerized sucralfate, sometimes called high potency sucralfate or polymerized cross-linked sucralfate is a new sucralfate formulation recognized by the US FDA in 2005. Positive clinical data from three randomized controlled trials using pre-polymerized sucralfate for GERD and NERD was first reported in 2014 AGA's Digestive Disease Week (DDW).

Gastric refluxate contains protonic acid, dissolved bile acids and proteases each of which cause classic mucosal reactions in the esophageal epithelium. These reactions are symptomatic but may or may not involve erosions. Pre-polymerized sucralfate utilizes biophysical means to exclude all three irritants from epithelial mucosa.

Being non-systemic, the entire clinical effect of any sucralfate rests in the surface concentration of sucralfate achieved. Pre-polymerized sucralfate, presented in 2014 DDW, and discussed here, achieves a surface concentration that is $800 \%$ greater than standard sucralfate on normal mucosal lining and 2,400\% greater on inflamed or acid-injured mucosa.

To understand the biomolecular basis of its clinical effect, this review re-introduces the reader to mucosal barrier, discloses the exact site of engagement of sucralfate, and how transient sucralfate-mediated biostructural changes in extra-cellular mucin is translated into intra-cellular signaling that modules the mucosal reaction to refluxate.

A broad-based literature review will not only aid understanding of the molecular basis of sucralfate's clinical effects, but will also provide context for an informed impression of whether pre-polymerized sucralfate has a role in the management of GERD and NERD.
\end{abstract}

\section{Keywords}

Polymerized sucralfate, NERD, GERD, Regulatory dichotomy

\section{Introduction}

The superior performance of acid-controlling therapies, namely proton pump inhibitors (PPI) and histamine-2 receptor antagonists (H2RA), eroded the early but tenuous role of sucralfate in the treatment of gastroesophageal reflux disease (GERD), which role had resulted from off-labeled use (mission creep) of sucralfate's original prescription indication for duodenal ulcers. The clinical performance of standard sucralfate dosed at $14 \mathrm{mg}$ per $\mathrm{kg}$ ( 1 gram) four times daily was inconsist and underwhelmed clinicians and led to its exclusion from most clinical guidelines for GERD [14]. Sucralfate had been largely unimpressive for either erosive GERD (eGERD) or for NERD, non-erosive gastroesophageal reflux disease. There were two notable exceptions - a trial conducted by Simon, et al. [5] in NERD patients using a mucoadherent gel formulation of sucralfate (twice as potent as sucralfate suspension in terms of retention within gastrointestinal (GI) tract $[6,7]$ and a trial conducted by Vermieidien, et al. [8] using sucralfate suspension for eGERD. In the former study [5], a $14 \mathrm{mg} / \mathrm{kg}$ dose of sucralfate gel (1 gram) given twice daily for 42 days resulted in symptom relief for $71 \%$ of NERD patients compared to $29 \%$ on placebo. In the latter study [8], a similar dose of sucralfate suspen- 
sion ( 1 gram) given four times daily for 56 days resulted in symptomatic relief in $72 \%$ of eGERD patients with a corresponding healing rate of $68 \%$. Given that sucralfate works by coating the mucosa [9], a perception prevailed that $a$ its suspension was better than the tablet which must dissolve before coating, and (by extension) its gel was better than suspension due to mechanical retention of sucralfate coating $[6,7]$ by the gel. This perception implied that the formulation of administered sucralfate could be determinative of its clinical effect.

In 2005, the US Food and Drug Administration (FDA) recognized a new formulation sucralfate, pre-polymerized sucralfate [10], which it currently regulates as a medical device, a form of a barrier therapy.

Comparatively, low doses of pre-polymerized sucralfate suspension (1.5 gram bid versus 1 gram qid) unexpectedly demonstrated efficacy in both eGERD and NERD patients with 1 week $80 \%$ complete healing of eGERD and 4 week $83 \%$ reversal of symptomatic NERD [11].

Obviously a review of any plausible role of sucralfate in the management of eGERD and NERD requires an understanding of how medicinal formulation (namely pre-polymerization) meets and results in clinical function. This report will underscore particulars of three randomized controlled trials that used low dose pre-polymerized sucralfate to achieve positive outcomes in undifferentiated NERD and in erosive GERD. But first what is the nature of the disease, and specifically, what is the pathophysical challenge posed by GERD against which pre-polymerized sucralfate must work? In short there are three main irritants in gastric refluxate creating two mucosal reactions.

The Challenge of Reflux Disease - Several Irritants, Several Mucosal Reactions

Whether erosive or non-erosive, the symptoms and signs of GERD arise from a mucosal reaction to the backwash of gastric refluxate. Physiologic reflux is asymptomatic, endoscopically normal and presumably without histomorphological consequences [12]. Continuous manometric recordings of esophageal $\mathrm{pH}$ and show that there are short episodes of acid reflux in the normal population generally following meals and uncommonly at night when recumbent [13-15]. Early observations included that a) Complete absence of lower esophageal sphincter (LES) pressure was essential for reflux; b) At low LES any elevation of intrabdominal pressure increases frequency reflux events and c) In asymptomatic recumbent subjects reflux is related to transient inappropriate LES relaxation rather than low steady-state basal LES pressure. But the occurrence of heartburn heralds a likely advent of histomorphologic changes.

According to Rome IV classification [16,17], symptomatic reflux is either erosive or non-erosive. Non-erosive heartburn associated with normal reflux fre- quency is known as esophageal reflux hypersensitivity syndrome [18]. Non-erosive heartburn that is unrelated to reflux episodes is termed functional heartburn. Non-erosive heartburn associated with abnormally frequent reflux is classic NERD as oppose to functional NERD of esophageal reflux hypersensitivity and functional heartburn.

Symptom perception to acid and mucosal integrity are inextricably linked [19-21] and it so happens that whether erosive GERD, or either of the two functional NERD or classic NERD syndromes, symptomatic reflux is associated with some degree of histomorphologic alterations in the esophageal mucosa $[22,23]$. In essence, regardless of clinical phenotype, symptomatic heartburn signals a material breach of esophageal epithelium, if even the mucosal reaction is cellular and escapes gross visible changes in tissue appearance.

Regardless of tissue appearance by endoscopy, these tissue biopsy reveal cellular alterations facilitated by reactionary immune events in the mucosa [24-27]. These events are effectuated by pro-inflammatory cytokines $[28,29]$ and present as dilated intercellular spaces within the esophageal epithelium $[22,30]$.

Afferent innervation of the esophagus by the vagus nerve is a shared characteristic of all Rome IV GERD patients [31] and there are differential submucosal depths of neurosensory nociception, with afferent pain fibers being more shallow in the proximal esophagus [32]. Heartburn sensation arises from firing of sensory neurons in the distal esophagus, and indicates a histochemical disturbance within the mucosa which excite submucosal nociceptors [33] and upregulate afferent neurons to release painful neurokinnins and to elevate hyperalgesia by increasing the expression of nociceptors. Nociceptors are in flux voltage gated receptors classified as acid sensing ion channels (ASIC) [34] and as transient receptor potential vanilloid receptors (TRPV) [35]. These receptors require continual transmucosal flux of ions (positive with negative ion exchange) to keep afferent neurons switched-on during GERD episodes.

The lack of symptom response in some GERD patients to PPI's, H2RA's and antacids imply existence of histochemical processes exclusive of $\mathrm{pH}$. In fact, observations that both $\mathrm{pH}$-responsive and $\mathrm{pH}$ - non-responsive NERD patients exhibit dilated intercellular spaces in the esophageal epithelium [22] and basal cell hyperplasia beyond that of controls [23], suggest that mucosal reaction in functional and classic NERD is not simply a problem of acid content $(\mathrm{pH})$ of gastric refluxate. Within gastric refluxate there are least three irritants that illicit pain, neuro-excitation and subepithelial (lamina proprial) cytokine inflammation - protonic acid, dissolved bile acid and proteases (trypsin, chymotrypsin and pepsin). Dissolved conjugated bile is as culpable as acid [36-39], 
in causing intercellular dilation $[40,41]$. Bile acids elicit mast-cell mediated upregulation of pain receptors in the lower esophagus [42] as well as cytokine-driven inflammation from reflux [29]. These alterations in immuno-homeostasis and changes and associated histomorphology give rise to higher transepithelial permeability and lower extracellular impedance observed in the esophagus of patients with functional heartburn, GERD and NERD [21].

In recumbent patients, mineral acid (hydrochloric acid) and bile reflux together $[39,43]$ and reflux events containing bile may be more numerous than reflux events of acid alone [44]. Dissolved bile acids, particularly taurine conjugates of cholic acid and chenodeoxycholic acid [36,37], aren't deterred by acid-controlling therapies, and there is evidence to suggest, that perhaps elevate $\mathrm{pH}$ may facilitate exposure to dissolved bile [38]. So both mineral acid and dissolved bile acids co-dependently and independently initiate pro-inflammatory immunologic processes $[24,25,28,45]$ raising the question whether inflammatory cytokines rather than caustic acid creates symptomatic GERD $[29,46]$ In both erosive GERD, functional heartburn and classic NERD, the presence of reflux events (mixed acid and bile) increases the submucosal expression of interleukin-8 (IL8), of TRPV1 for acid nociception and of nerve growth factor (NGF), which hypersensitizes afferent sensory nerve function $[47,48]$.

In patients with NERD, the quantity of lower esophageal mast cells is nearly doubled compared to controls, and the percentage of degranulated mast cells is elevated as well, $27 \%$ versus $12 \%$, respectively [26]. Bile acids are known to trigger mast cell degranulation in the lamina propria which in turn induces visceral hypersensitivity (pain) through the post-degranulation release of nerve growth factor [42].

Serine proteases present in gastric refluxate also illicit mucosal immunoreactions. Typsin induces mucosal secretion of IL-8 and impair epithelial barrier [49], negatively modulate tight junction proteins thus undermining mucosal integrity [50] and illicit a d 10 fold upregulation of the proteinasse-activated receptor-2 (PAR-2) gene throughout the epithelial layers, which is associated with enhanced IL-8 expression, papillary elongation, basal cell hyperplasia, and dilated intercellular spaces in esophagus of patients with eGERD [51].

\section{Countering Exposure and Consequences of Re- curring Refluxate}

Clearly, the physiologic cause of the symptom and signs of GERD, whether erosive or non-erosive, is caused recurrent exposure to gastric refluxate that contains protonic acid, dissolved bile acids and serine proteases. The mucosal immuno-reaction and subsequent histomorphologic alterations are a consequence of repeated physical exposure to gastric refluxate. Thus a reasonable therapeutic approach in management GERD would be interventions that physically deny gastric refluxate (and by extension its caustic contents) access to the mucosal lining of the esophagus. An esophageal coating agent such as pre-polymerized sucralfate could physically deny refluxate recurrent access to the underlying mucosa.

The notion of a therapeutic esophageal coating is a pragmatic concept easy for patients to understand. But prescribing such a therapy requires practitioners to understand the medicinal chemistry, mode of action and regulatory background of pre-polymerized sucralfate as well as the dynamics of the 'terms of engagement' (so to speak) it has with its mucosal target. The 'terms of engagement' that sucralfate has with its mucosal target are the biophysical determinants of that target, how those determinants relate to the integrity of the mucosal barrier and are parlayed into observable clinical effects of sucralfate.

The concept of that the sucralfate barrier is like an adhesive "bandaid" oversimplifies the parallel cascades of events put in motion by the coating action of pre-polymerized sucralfate on the mucus gel.

A more nuanced understanding of events resulting from the coating action of pre-polymerized sucralfate, involves the functional physiology of an intact mucosal barrier as well as the medicinal chemistry of pre-polymerized sucralfate.

To this point, and as will be discussed later, the mucosal barrier and its integrity is more than tight junction proteins, the presence or absence for dilated intercellular spaces. Rather, there are three distinct histologic compartments, with their respective structural elements intertwine by at least seven interrelated and codependent physiologic functions that are distributed among the three compartments.

Ultimately the homeostatic operation of the seven functions is protected by the corporeal integrity of the mucus gel compartment, the compartment targeted by the coating of pre-polymerized sucralfate.

Physical coating of pre-polymerized sucralfate thwarts access of the three main gastric irritants to the esophagus epithelium and simultaneously exerts a physiochemical order within the mucus gel which in turn is translated to the epithelium biophysically for the enterocyte to modulate processes of inflammation. Biophysical communication between mucin of the mucus gel and the esophageal epithelium is converted into intracellular communication controlling pivotal levers of inflammation. The concept of barrier therapy is simple, but the mechanics whereby barrier action is converted into clinical effects has gradation.

Having described the challenge of reflux disease in terms of three chief causative irritants and mucosal reactions to those irritant, this report turns to the history 
of sucralfate, its regulatory dichotomy, the medicinal chemistry of pre-polymerized sucralfate and the biological basis for its clinical actions. Any role for pre-polymerized sucralfate would require this as a foundation. In covering the biological basis of sucralfate effect, an updated perspective of the mucosal barrier targeted by sucralfate will be provided. Covering the molecular basis of action, the report describes how the sucralfate-mucin engagement specifically denies refluxate access, creates immediate positive consequences from that denial and indirectly leads to epithelial signaling that is ultimately responsible for the positive clinical outcomes of sucralfate coating. A synopsis of the three randomized controlled trials will lead to a conclusion as to whether there is a role for pre-polymerized sucralfate in the management of GERD.

First, the background on sucralfate, its regulatory history, medicinal chemistry and biological basis of action.

\section{History and Regulatory Dichotomy of Sucral- fate}

\section{History of sucralfate}

Sucralfate is a synthetic analog of a unit of gastric mucin. Discovered in 1968, it represented the culmination of academic quests dating from 1772 [52-54] a quest to understand why the stomach did not digest itself. The 1907 theory of mucoprotection by gastric mucus [55], sparked investigational interests in gastric mucus, with subsequent discovery of mucin and 'mucoids'. Efforts to decipher mucin's structure between 1911 [56] and 1918 [57] led researchers to concluded in 1920 that the theory of mucoproctection by gastric mucus was a fact [58]. The period from 1930's through the 1950's was subsumed with deciphering the physiologic performance of gastric mucin $[59,60]$, its clinical application for the treatment of peptic ulcer [61] and led to the discovery that the chondroitin sulfate fraction of mucin was pepsin-suppressing and mucoprotective [62]. Understanding matured regarding the gastric mucus barrier and its secretions from 1940 to 1950 [63-66] and studies on the therapeutic antipeptic value of sulfonated polysaccharides projected from the 1950's into the late1960's [67-71].

Academic efforts in Japan expanded from sulfonated polysaccharides to sulfonated analogs of oligosaccharides (chain of three to nine sugars), disaccharides and monosaccharides. In 1966, this led to the synthesis of octasulfonated sucrose, whose aluminum hydroxide salt was called sucralfate [72].

\section{Regulatory history}

Full descriptions of its antipeptic properties [73] and published results of multi-centered clinical trials [74] resulted in sucralfate first regulatory approval for human use in Japan in 1968. The 1969 US Patent on sucralfate [75] was followed thirteen years later with the 1982 US FDA approved New Drug Application (NDA) \#18333 [76] for sucralfate solid dose form (Carafate) to treat duodenal ulcers. This was followed in 1993 by US FDA approval of NDA \#19083 [77] a $10 \%$ suspension of sucralfate for the treatment of duodenal ulcers. From 1993 to date there are over 214 brands of sucralfate tablets, suspensions or powders formally regulated by more than 69 countries [78]. Sucralfate has a reputation for being a safe drug, associated with few adverse reactions and non-specific absorption of concomitantly administered drugs that had electronegative properties. Despite widespread use, its safety profile has remained much the same as initially observed over the first 13 years of its first approval in Japan [79]. Regulatory authorities in 13 countries have granted over-the-counter (OTC) status to sucralfate tablets, suspension and powders resulting in 1.67 billion people having access to sucralfate drug without pharmacists's or physicians' order. For the remaining 5.8 billion people, however, sucralfate remains by prescription only.

\section{Regulatory dichotomy of sucralfate as medical de- vice- US FDA 2005 to 2013}

Whether in tablet, powder or suspension, each dose form of sucralfate is biologically inert and requires activation by gastric acid to polymerize it into its active form. This "chemical action" within the body, classifies standard sucralfate as a drug by all regulatory bodies. However, in 2005, the US FDA recognized a regulatory dichotomy for sucralfate. Their position was detailed in an Agency Product Designation Ruling known as an RFD, request for designation [10]. The RFD process involved a joint agency review of the original mechanism of action for sucralfate by the Center for Drug Evaluation and Research (CDER) and the Center for Device and Radiological Health (CDRH).

Sucralfate drug had been classified by the CDER as a non-systemic site protective agent requiring post-ingestion polymerization to selectively engage (coat) fibrinous debris and mucin [80,81]. In their RFD of 2005 [10], the FDA made a finding of fact that if sucralfate is polymerized before ingestion, or pre-polymerized, then it is being used as a medical barrier device, having a physical mode of action and requiring no further chemical action to be clinical active. Since this clarification the FDA has maintained two regulatory statuses for sucralfate - a status as a drug for non-polymerized sucralfate prepackaged in its unpolymerized biologically inert form, and a status as a medical device for sucralfate pre-polymerized prior to patient use.

In 2013, under the 510K program of the $\mathrm{CDRH}$, the FDA licensed the first commercially distributed pre-polymerized sucralfate barrier therapy medical devices. 
The suspension formulation of this pre-polymerized sucralfate studied in the three randomized GERD trials is Esolgafate.

\section{Medicinal Chemistry of Polymerized Sucralfate}

Sucralfate polymerization is simply ion-facilitated self-annealing of sucralfate. Without polymerization sucralfate cannot work. There are three main forms of polymerized or self-annealed sucralfate, water-polymerized (WP) sucralfate, gastric acid polymerized (GAP) sucralfate as type of mineral acid polymerization, and organic acid polymerized (OAP) sucralfate. WP sucralfate results when moisture partially dissolves solid dose form of sucralfate, tablet or powder rendering a $40-70 \%$ concentration of sucralfate. Applying sucralfate powder or crushed sucralfate tablets to moisture (a moist wound) or to drops or water creates WP sucralfate. Less than $40 \%$ concentration, hydrogen bonding within water overrides ability for sucralfate to self-anneal with limited moisture. Exposure to gastric acid also polymerizes sucralfate. Original endoscopic examinations of sucralfate $[9,82]$ reveal partially dissolved/polymerized sucralfate adherent to the gastric mucosa as GAP sucralfate. It is more resistant to hydrogen-bond mediated hydration. Non-gastric hydrochloric acid can be used to create mineral acid polymerized (MAP) sucralfate which was the subject of the RFD by the US FDA [10]. The use of organic acids to polymerize (OAP) sucralfate creates a more resilient amorphous polymerized product.

OAP sucralfate utilizes weak organic acids such as acetic acid to polymerized sucralfate. Pre-polymerized sucralfate used in the clinical trials was cationic organic acid facilitated self-annealing or polymerization. While WP, GAP and MAP are sensitive to water hydration, thereby more easily washed away, OAP is less sensitive to water hydration thereby maintaining longer physical presence on the mucosal lining.
Table 1 provides a qualitative perspective on the presence of polymerization and its weakness or vulnerability to disruptive hydration and dissolution by water. As the degree of polymerization increases, the vulnerability to disruptive dissolution diminishes. Once the surface concentration of sucralfate on the mucosal lining sustains a significant drop off, then the clinical effect of sucralfate is lost.

Just as gel formulation of sucralfate remains mucoadherent for at least 1 hour following ingestion $[6,7]$, so too there is both prolonged mucoadherence and enhanced muco-concentration of sucralfate with the pre-polymerized sucralfate used in the three trials. Figure 1 shows that 3 hours post-administration, this form of pre-polymerized sucralfate achieves and maintains a surface concentration of sucralfate that is 7 fold (or $800 \%$ ) greater on normal mucosa and 23 fold (or 2400\%) greater on acid-injured mucosa compared to gastric-acid polymerized sucralfate [83]. Enhanced muco-retention was expected. But enhanced muco-concentration of sucralfate was not and is believed to occur post ingestion due to ionic preference of sucralfate polymerized by a weak organic acid in the presence of cations to self-anneal in situ. This suspected post-ingestion hyper-self-annealing in situ may occur in a manner simi-

Table 1: Qualitative Degree and Strength of Polymerization.

\begin{tabular}{|l|l|}
\hline Sucralfate Entity & Degree of Polymerization \\
\hline Sucralfate tablet/powder (inert) & None \\
\hline Sucralfate Suspension (inert) & Minimal \\
\hline WP-Sucralfate & Moderate \\
\hline GAP/MAP - Sucralfate & High \\
\hline OAP-Sucralfate & Extreme \\
\hline
\end{tabular}

WP- water polymeration ; GAP- gastric acid polymerization; MAP- mineral acid polymerization; OAP - organic acid polymerization

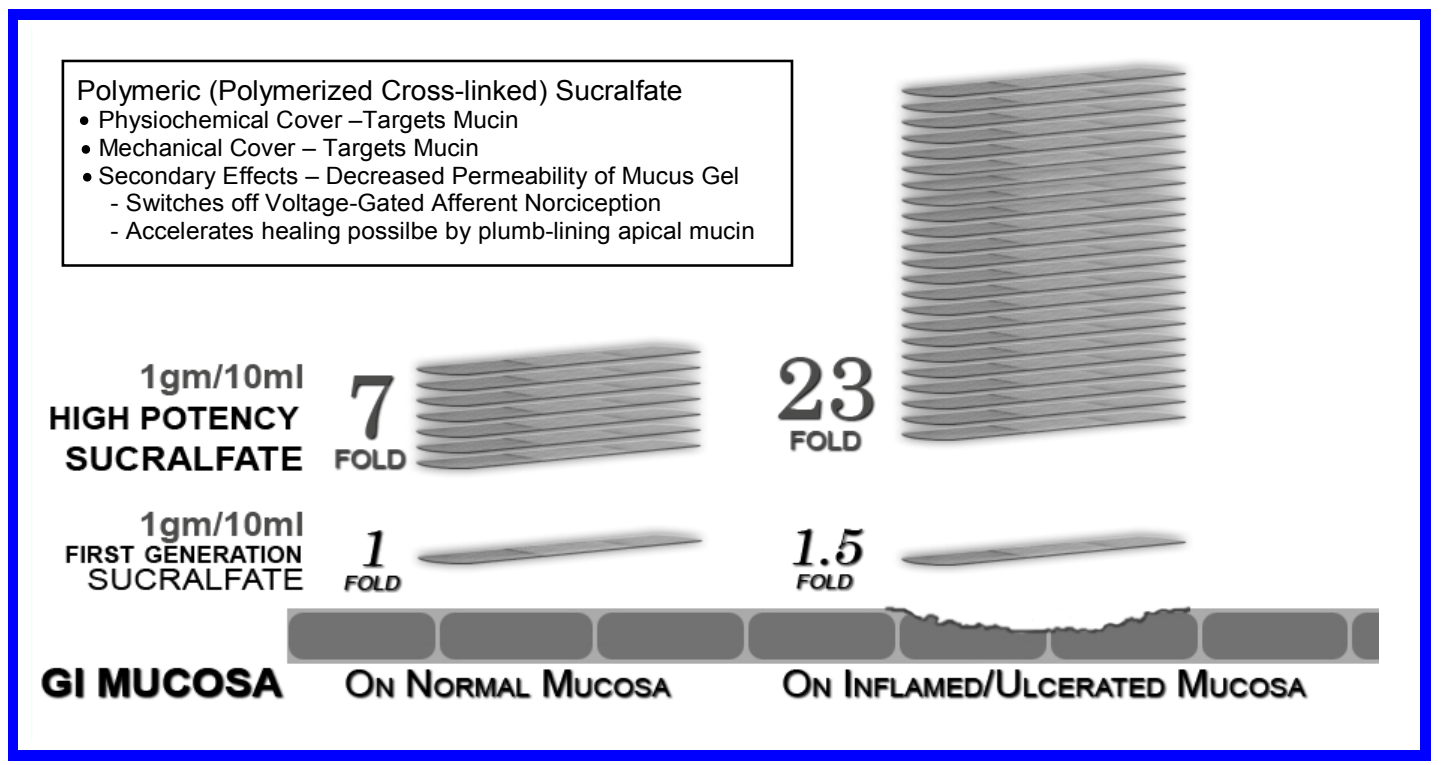

Figure 1: Exaggerated Muco-adherence Polymeric Sucralfate - 3 hours Post-administration. 
lar to pi-stacking [84], a extra-molecular phenomenon where given stereotactically mobility electrostatic substituents, there is heightened electrostatic self-attraction of compounds in hydrophobic manner to exclude water when placed in the setting of water ubiquity. In essence non-covalently bonded sheets of sucralfate amass upon the mucosal lining.

\section{Biological Basis of Sucralfate's Therapeutic Ac- tion}

Sucralfate is non-systemic cytoprotectant expelled from the colon in chemically unaltered amounts that are $95 \%$ to $98 \%$ of ingested dose [85]. Being a therapy that relies on coating the mucosal lining, the entirety of its clinical effect resides in the surface concentration of sucralfate that can be achieved and/or maintained.

Polymerized sucralfate barrier therapy preferentially engages mucin, the biophysical cover of the enteric mucosa [86-88]. Neither denuded epithelium, its apical surface, nor growth factors located on its basolateral membrane provide areas of engagement for sucralfate. Because near immediate mucosal reactions occur (epithelial regeneration, mucus secretion, prostaglandin release etc) when large concentrations of dissolving sucralfate adhere to the mucosa, some researchers have asserted that clinical effects of sucralfate emanate from its molecular engagement of growth factors expressed on enteric epithelium [89]. However, epithelial-associated growth factors are located on basolateral surface beneath epithelial tight junctions and not near surface facing the lumen where sucralfate is retained.

Additionally, from 30 years of basic science research on sucralfate (from 1987 to 2017) in vitro, in vivo with and without growth factors, no evidence has emerged to support sucralfate-growth factor interaction as the seminal event driving its cytoprotective actions.

Rather considerable evidence suggests that no working relationship exist between luminal sucralfate and epithelial bound growth factors $[90,91]$. Instead, transmission electron micrographs, scanning electron micrographs and unfixed freeze-fractured, and freeze-dried electron micrographs demonstrate that sucralfate prefers mucin or fibrin for binding and that none adheres to or lies near apical epithelium of the GI tract, even over epithelium denuded of mucin or fibrin $[86,87]$. Clearly post-ingested sucralfate can be found bound to the mucin gel compartment in a manner of decreasing gradient from the outer to inner aspect of the mucin layer [88].

The biophysical nature of mucin's relationship with enteric epithelium holds the key for sucralfate's clinical effects. From the author's research, it seems that the structural reaction of mucin to the transient coating of sucralfate is parlayed into mucin-directed molecular effects within the mucosal lining. These mucin-directed molecular efffects culminate into cytoprotective clinical effects of sucralfate. Thus, it seems, that without the physical material effect of a sucralfate coating on the biophysics of mucin, cytoprotective clinical effects of sucralfate simply would not occur.

\section{Early experimental observations of mucosal reac- tion to sucralfate - Rapid \& Dramatic}

Running in parallel to approved clinical uses of sucralfate from 1982 through 1995, were translational medicine research on the physiologic basis of the clinical effects of sucralfate. Early observations, well chronicled by Hollander and Tygat [92], were dramatic and occurred rapidly. Immunologic understanding of the enteric mucosa was in its infancy at that time, so many of the histologic, ultrastructural and functional reactions of the mucosa to sucralfate while observed was not well understood. The mucosal events were as follows. First, as stated above, sucralfate targeted mucin and not bare epithelium. Its adherence seen by endoscopy was with mucin within the mucus gel [86-88]. Secondly, sucralfate's engagement with mucin strengthen the integrity of the gel and did so in a dose dependent fashion [93]. There was an immediate multifold enhancement of mucus viscosity, a $60 \%$ increase in its hydrophobicity which in turn causes decreased permeability of a) hydrogen ions (acid) [94]; b) cations (e.g., calcium) [95]; and c) bile acids [96]. Sucralfate engagement of mucin inhibited endogenous proteases (pepsin, trypsin and chymotrypsin) [97] and exogenous mucolytic proteases of Helicobacter pylori $[98,99]$.

Thirdly, endoscopic examination of partially dissolved, partly polymerized sucralfate tablets resting on the greater curvature of the stomach, revealed near immediate histologic, ultrastructural and functional changes occurring within the epithelium circumferientally around the partly dissolved, partly polymerized sucralfate fragments $[100,101]$. Specifically from 5 to 60 minutes, sucralfate's non-chemical electrostatic physical engagement of mucin, led to increased mucin release, increased luminal release of prostaglandin E2 and signs of epithelial cell renewal generally centered at the physical site of contact with partially polymerized sucralfate tablet, which was adherent [100]. At that time, in 1986-88, the importance of sucralfate's engagement of mucin was not connected to these mucosal events, because the physiology of mucin was not that well understood and its biophysically connected humoral relationship with the enterocyte was not broadly studied. So the connections provided in this report could not have been made at the time.

But what was clear, now in hindsight, is that the reasons for rapid and dramatic changes observed at the time was that doses used in experimental animals was 5-10 fold the usually $14 \mathrm{mg}$ per $\mathrm{kg}$ dose permitted in clinical practice. Even the in vivo observations in human subjects were of partially dissolved, polymerized fragments of sucralfate tablets which in essence replicated the multifold dosages given to experimental animals. 
What Tarnawski, et al. [100] saw in humans endoscopically were the effect on $5-10 \mathrm{~cm}$ concentric area of stomach hosting in its center a 1 gram half dissolved tablet of polymerized sucralfate sitting on the stomach's greater curvature. The dose of sucralfate received by mucin overlying that $5-10 \mathrm{~cm}$ concentric area was far greater than the $14 \mathrm{mg}$ per $\mathrm{kg}$ dose for an entire $70 \mathrm{~kg}$ patient.

In 1987 the reasons those observations occurred were unclear, largely because the physiological link between mucin and the underlying epithelium had not been elucidated. To understand how pre-polymerized sucralfate can be effective in NERD and how it can be causally associate with $80 \%$ complete healing of eGERD in 7 days it is necessary to review current knowledge of enteric mucosal barrier.

\section{The enteric mucosal barrier coated by polymer- ized sucralfate}

In 1987, investigators didn't have the advantage of 30 years of research that has transpired in understanding the physiology of the enteric mucosal barrier.

A brief overview of this understanding is useful in appreciating just how dose-dependent sucralfate coating in the mucus layer can be parlayed into the clinical effects reported in the three controlled trials involving Esolgafate.

As shown in Table 2, there are three histological compartments of the mucosal barrier and they include the mucin (mucus gel) compartment, the single-cell epithelial compartment and the sub-epithelial compart- ment or lamina propria [102].

For perspective, the single-cell epithelial layer has associated lower layers of basal epithelial stem cells riding above the lamina propria within which the basolateral surface of the enterocyte (situated below the epithelial tight junctions) participates as a functional member of the submucosal lamina propria. The submucosa hosts immune cells (mast cells, monocytes, macrophages, neutrophils, basophils, Band T-lymphocytes), neuro-fibers specialized with nociceptors and capillaries lined with malleable endothelium. The single-cell epithelium is 20 microns, its apical transmembrane mucin of the glycocalyx is 0.5 to 1.5 microns, above which is an adherent layer of mucus (absent in distal esophagus [103]) of $30 \mathrm{mi}-$ crons. Above the 30 micron adherent layer of mucus is a $200-450$ micron layer of loosely adherent mucus layer, which in the esophagus is supplied by the salivary gland secretions, submucosal goblet cells and apical epithelial membrane.

While somewhat beyond the main focus of this report, it is worth mentioning that there are at least seven barrier functions conducted across three histological compartments as shown in the Table 2.

Listing these functions provide perspective to the meaning of cytoprotective homeostasis provided by sucralfate coating of the enteric lining. Continuous homeostatic functions of the mucosal lining include 1) Functions to cover, capture, deflect then remove luminal assailants and 2) Functions to neutralize lu-

Table 2: Structural Biology and Function of a Healthy Mucosal Barrier.

\begin{tabular}{|c|c|c|c|}
\hline $\begin{array}{l}\text { Barrier } \\
\text { Compartments }\end{array}$ & \multicolumn{2}{|c|}{ Barrier Functions } & \multirow{2}{*}{$\begin{array}{l}\text { Functional \& Cellular Elements } \\
\text { Loose Mucin labyrinth, sterile dense Adherent Mucin, Mucin Transient }\end{array}$} \\
\hline \multirow{2}{*}{ Mucins } & 1 & $\begin{array}{l}\text { Cover, Capture, Deflect, } \\
\text { Remove }\end{array}$ & \\
\hline & 2 & Neutralize and Preserve & $\begin{array}{l}\text { Neutralize using IgA, anti-microbial agents, detached transmembrane } \\
\text { mucin; Preserve epithelium using trefoil factors (TFF1,TFF2,TFF3) }\end{array}$ \\
\hline \multirow[t]{2}{*}{$\begin{array}{l}\text { Single Cell } \\
\text { Epithelium }\end{array}$} & 3 & $\begin{array}{l}\text { Antigen \& non-antigen } \\
\text { Surveillance, Detection, } \\
\text { Barrier lubrication \& } \\
\text { Sustenance }\end{array}$ & $\begin{array}{l}\text { Sample surveillance by } \alpha \beta-I E L, \delta y-I E L, M-c e l l s, \text { dendritic cells, goblet } \\
\text { cells; detect mucin disturbance by epithelial transmembrane mucin; } \\
\text { lubricate and sustain epithelium by Globlet cells producing mucin, trefoil } \\
\text { factors; tuft cells and enteroendocrine cells. }\end{array}$ \\
\hline & 4 & $\begin{array}{l}\text { Cap and Close off } \\
\text { Luminal Contents }\end{array}$ & $\begin{array}{l}\text { Epithelial Cells with toll-like receptors, tight junctions, epithelial cytokine } \\
\text { production, apical transmembrane mucin \& cytosol signaling, basolateral } \\
\text { growth factors }\end{array}$ \\
\hline \multirow{3}{*}{$\begin{array}{l}\text { Lamina Propria and } \\
\text { Submucosa } \\
\text { to Subserosa }\end{array}$} & 5 & $\begin{array}{l}\text { Pre-emptive Immune } \\
\text { Actions }\end{array}$ & $\begin{array}{l}\text { Innate Immune Cells (ILC) - Class I, II, III interacting with epithelial cells, } \\
\text { IEL's, Globlet cells, Dendritic cells, M-Cells }\end{array}$ \\
\hline & 6 & $\begin{array}{l}\text { Adaptive Counter-Attack } \\
\text { Immune Actions }\end{array}$ & $\begin{array}{l}\text { Monocytes, Macrophages, Mast Cells, B- Lymphocytes, T-Lymphocytes, } \\
\text { inflammosome formation }\end{array}$ \\
\hline & 7 & $\begin{array}{l}\text { Host Warning and } \\
\text { Eliminate Effluent }\end{array}$ & $\begin{array}{l}\text { Enteric glial neurons with } 2 \text { classes of voltage-gated receptors (ASIC, } \\
\text { TRPV) on afferent neurons, with input to efferent neurons that are } \\
\text { responsive to cytokine secretions from IEL, epithelial cells, mast cells } \\
\text { and ILC's; these neurons extend from the epithelial cell layer (including } \\
\text { tuft cells and enteroendocrine cells) downward into the submucosal } \\
\text { plexus and myenteric plexus, with functions for sensory, epithelial, } \\
\text { vascular, pain, nausea, emesis and motility. }\end{array}$ \\
\hline
\end{tabular}

IEL- intra-epithelial lymphocytes; ILC- Immune Lymphoid Cells; ASIC- acid sensing ion channels; TFF- trefoil factors; TRPVtransient receptor potential vanilloid 
minal offenders and preserve physical epithelial structure covering the submucosa, group functions overseen by the mucus gel. Then 3) Functions of antigen and non-antigen surveillance, detection, barrier lubrication and sustenance and 4) Functions to cap and close out luminal contents using tight cell to cell attachment proteins, which are group functions overseen by the single cell epithelium. Then lastly there are the 5) Pre-emptive immune activity by innate immune cells, the 6) Counterattack pro-inflammatory actions of the adaptive immune cells and 7) The functions that warn host through the enteric nervous system, secretory chemosensor cells that can initiate rapid (cathartic) elimination offending luminal contents, a third group function domain of the lamina propria.

These seven barrier functions distributed across three histological compartments are provided cover by the mucin gel which requires the biophysical stability, generally provided by luminal coating of sucralfate. Mucosal homeostasis is served seamlessly by these seven barrier functions, which in turn are all preserved by the biophysical integrity of overlying mucin. Irritants of gastric refluxate penetrating the mucin gel is detected by nociceptors of afferent neurons (registered as pain) as they incite inflammatory reactions within the submucosa, reactions that affect normal differentiation of esophageal epithelium. Thus the integrity of the mucin gel compartment is physically linked to the health of the epithelial and subepithelial layer of the esophagus. It is also the targeted site of engagement for pre-polymerized sucralfate.

\section{Biophysical Integrity of the Mucin Gel Rein- forced by Sucralfate}

The mucin compartment, targeted by sucralfate, is comprised of two distinct mucus layers that have a rapid turnover. It is estimated that the mucus gel is replaced at least 17.8 times per 24 hours, being calculated from the rate of mucus turnover in the rat [104-106] comparatively correlating it to the entire human GI tract [107]. Up to 10 liters of mucus is secreted into the GI tract daily [108]. Mucin are glycoproteins comprised of more than $80 \%$ carbohydrate [109], having a linear protein structure with covalently bonded with branched glycans at the hydroxyl group of threonine and serine, giving mucin compound a bristled bottle-brush appearance. Distributed along the protein strand are cysteine-rich domains that permit intermolecular bonding to form dimeric and multimeric mucin. Multimeric mucin is then packed through hydrogen bonding into mucin networks with varying degrees of hydration. Containing large amounts of water covert mucin networks into gels. The glycans in gel forming mucins resist breakdown by digestive enzymes and function to structurally protect and lubricate the oropharynx and GI tract. It is here where pre-polymerized sucralfate work to exact its clinical effects.

Corporeal integrity of the esophageal mucosa rests with epithelial cells structurally fitted with apical calyxes of transmembrane mucins interwoven and fasten by cysteine rich 'midpoints of MUC2 mucin strands within the overlying adherent mucus gel [110]. Epithelially attached transmembrane mucins are interwoven largely into the adherent mucin gel and to a lesser extent into the loose layer of mucin. Trefoil factors derived from adjacent goblet cells are induced by neighboring epithelial cells that express transmembrane mucins. Multimeric complexation of trefoil factors with the glycocalyx acts as 'antennae stabilizers', significant alteration of which can trigger cytosol release of intracellular sections of transmembrane mucin. Freed intracellular sections of transmembrane mucin then participate in signaling pathways that modulate the transcription of pro-inflammatory and anti-inflammatory effector molecules (e.g., NF-kB). The type, extent and quality of cytosol signaling will vary in accordance to the type of transmembrane mucin involved (MUC1, 3, 4, 12, 13, 16 or 17). Biophysical stabilization of mucin facilitate continuance of homeostatic processes, occurring both within the mucin compartment and most importantly in the underlying epithelial and lamina proprial compartments.

The second layer of mucin is less soluble adherent layer of mucin [110] generally devoid of bacteria [111], with transmembrane mucin interwoven into the adherent layer distally, but attached to the apical surface of the epithelial cells proximally. Seven structurally distinct transmembrane mucins (MUC1, MUC3, MUC4, MUC12, MUC13, MUC16, MUC17) form the enterocyte glycocalyx being bound centrally to epithelial and goblet cell membranes with distal dangling ends engaged in a mesh work of adherent MUC2 mucin forming sterile minimally hydrated mucus gel. This mesh work of adherent gel physically protects underlying cells from harm while their proximal intracellular ends are involved in intracellular pathways that regulate inflammation, differentiation, apoptosis and cell-cell interactions [112].

Distributed within both soluble and adherent mucus layers are three families of trefoil factors, TFF1, TFF2 and TFF3 [113]. Trefoil peptides share a 40-amino-acid sequence shaped as a three-leaf clover of covalent loops (trefoil domain) stabilized through three internal disulfide bonds between six cysteine (nonessential) amino acids, rendering trefoils resistant to degradation by protease, acid or heat. TFF1 and TFF3 contain a single trefoil domain, while TFF2 has two. But unlike TFF3, TFF1 and TFF3 have a free cysteine residue in their $\mathrm{C}$-terminal used to form covalent dimers with TFF peptides or other proteins (cysteine rich domains of mucins, which themselves aggregate in multimeric fashion).

Trefoil factors direct epithelial migration above the 
basement membrane of damaged or denuded epithelium $[114,115]$; it is a mucin-compartment process known as epithelial restitution. Trefoil factors are distributed along the epithelium within the adherent and soluble mucus gel. Trefoil-driven restitution is the first elemental step to restore barrier integrity and is generally completed within 10-30 minutes of injury [116].

Thus it can be imagined that concentrations of trefoil factor supplied to mucin layers by oral salivary glands and by epithelial and goblet cells of esophagus, stomach and colon are maintained at constitutive levels, so that, if needed, can be locally augmented through feedback control (e.g., cytosolic or nuclear pathways) to ramp up local production of trefoil factors.

In GERD, TFF3 expression is increased [117]. It is co-expressed from goblet cells with MUC 2 [118], considered to bind with von Willebrand factor $\mathrm{C}$ (VWFC) domain of mucins for oligomerization and resultant formation of a mucus gel of high viscosity [119]. VWFC domains are on MUC4 which are produced by epithelial cells, but in concentrations that are lower in eGERD compared to NERD and controls [120] therefore sensitive to presence of or the mucosal effect of acidic protons. It is overexpressed in tumor cells, notably so in breast cancer where it can bind ERB2, modulate its phosphorylation and signaling through ERrbB3. It can block cell and antibody binding to both normal and tumor cells, thereby repress apoptosis, a positive function for normal cells, but negative function for patients with tumor cells.

Normally MUC 4 elaborated by enterocyte for expression on its apical surface where it is associates with anti-adhesive properties of the enterocyte (creating a steric barrier for anti-body binding) and cytoprotection [121]. Because MUC 4 can be regulated transcriptionally (by multiple promoter sites via different transcription factors and signaling pathways), epigenetically (by DNA methylation or histone acetylation) and post-translationally by TGFß (through a proteosomal degradation) [121], it is likely a cytoprotective modulator activated by complexation with TFF3 or wildcard negative modulator if other.

\section{Molecular Basis of the Clinical Effects of Po- lymerized Sucralfate in GERD}

The site of sucralfate engagement on the mucosa, is not the epithelium, but mucin within the mucus gel $[86,88]$. This is unambiguous. The means by which the transient engagement of sucralfate with mucin convert into cytoprotection is better understood today than during the 1980's research of Tarnaswki, et al. [100,101], Hollander, et al. [122,123], Slomiany, et al. $[93,94,95,99]$ and others $[87,97,124-126]$. It would seem that the biological basis of the therapeutic actions of sucralfate (its engagement of mucin) is the molecular basis for its clinical effects. In the 1980's it was documented that dose-dependent engagement of sucralfate with mucin resulted in rapid ultrastructural, histological and functional reactions [100]. What is now understood, but at that time not well appreciated, were the structural nuances of the mucosal barrier, and particularly the structure-function relationship between mucin transmembrane mucins, trefoil factors [118], cytoprotective complexation of mucin [112] and the translation of mucin's biophysical into intracellular signaling pathways of the epithelial enterocyte $[112,127]$. Among the first molecular events of dose-dependent sucralfate-mucin engagement is (1) Enhancement of mucin viscosity [94], (2) The increase of hydrophobicity [93] and (3) Structural stiffening of mucus gel layer [93]. These physico-chemical changes are dose-dependent consequences of sucralfate coating. These changes deny permeation of protonic acid across the mucus gel compartment, thus slowing activation of ASIC and TRPV1 nociceptors, to silence pain. Enhanced hydrophobicity limits access of bile acids to cross the mucus gel compartment $[42,96]$ which both disallows activation ASIC and TRPV1 nociceptors and prohibits incitement of cytokine-mediated inflammation [29,47,48]. The electronegativity of sucralfate's dose-dependent engagement of mucin creates steric hindrance to proteases $[97,99]$ disallowing activation of PAR-2 receptors in the epithelium [128]. Sucralfate engaged mucin is also an electrostatic impediment of cationic ions (calcium, sodium and potassium) slowing their passage across mucous gel that is more hydrated [95]. Biomechanical stiffening of the mucin gel may provide structural transmission of biophysical signals to apical epithelium and goblet cells [127-129] by way of transmembrane mucins that stud their apical surface, triggering the cytoprotective secretion of trefoil, prostaglandin $E$, additional hydrophobic mucin and bicarbonate [100,101,123]. By barrier blockade of caustic acid, bile acids, serine protease and cations, the dose-dependent sucralfate-mucin engagement facilitate diminution of afferent firing of nociceptors (pain/discomfort relief), defervesce of cytokine-driven inflammation and reversion to normal mucosa, the healing process.

\section{Synopsis of Randomized Controlled Trials}

The five physical effects of a dose-dependent sucralfate-mucin engagement should issue in clinical effects on erosive GERD and NERD from pre-polymerized sucralfate that are not observed using standard sucralfate, because, as shown in Figure 1, at 3 hours post-administration, PPSBT achieves and maintains surface concentrations of sucralfate that are 7 to 23 times that of standard sucralfate. These elevated surface concentrations, i.e., enhanced potency, should parlay all five physical effects into positive clinical outcomes.

In the three randomized controlled trials [11] unexpected clinical outcomes did occur. In a word, the 
investigations demonstrated that in 7 days low dose of pre-polymerized sucralfate ( 3 grams daily) was better than placebo in the healing of erosive GERD when compared to omeprazole (40 mg daily), ranitidine (300 mg daily) or in 28 days it was better than placebo. Over 28 dyas, for patients with undifferiented NERD, 3gam of pre-polymerized sucralfate provided symptomatic relief better than placebo over 28 days in patients with either erosive GERD or undifferientiated NERD. Undifferiented NERD is a cohort of non- erosive GERD patients who have functional heartburn, esophageal reflux hypersensitivity and classic NERD in undetermined proportions. In general, $50 \%$ of undifferientiated NERD have classic NERD, while $30 \%$ have functional heartburn, and $20 \%$ have esophageal reflux hypersensitivity [130].

\section{PPSBT in Erosive GERD}

Each of the three trials were appropriately powered and had statistically relevant sample sizes of patients entered in to data analysis. Randomized participants of treatment groups were evenly represented in terms of gender, age, years of symptoms, presence of helicobacter and hiatal hernia. Participant attrition (those lost to follow up) was minimal, less than $12 \%$ on average and patient compliance with trial regi- mens was high [131]. Therefore reported outcomes were relevant under the controlled settings of trials. A daily total symptom score, comprised of number, type and severity of symptoms quantified by Likert Scale of 0 to 4 was used to compare pre-trial and post-trial scores. Heartburn, reflux sensation and retrosternal chest pain were among the symptoms evaluated. Healing was assessed by Hetzel-Dent grading system [132]. Complete healing occurred when there was endoscopic absence of erosions immediately following trial, that is a Hetzel-Dent Grade 0 or 1 . Partial healing was improvement by at least 1 Grade but still above Hetzel-Dent Grade 1 . No healing was noted when there was complete endoscopic absence of improvement in grade of erosions. Specific outcomes listed in Table 3 report symptomatic relief and healing from PPSBT over 28 days compared to placebo and from PPSBT over 7 days compared to omeprazole, ranitidine and antacids.

In 28 days, PPSBT reduced symptoms of heartburn and reflux sensation in $89 \%$ of participants compared to those using placebo (19\%). This is the first time any sucralfate therapy was associated with this outcome in trials performed in manner consistent with Cochran standard of minimal bias [133]. Similar symptomatic outcome was noted using PPSBT for 7 days. Figure

Table 3: Comparative Relief of Heartburn in Erosive GERD in 7 days and 28 days.

\begin{tabular}{|l|l|l|l|l|l|l|}
\hline Intervention & 7 day Antacids & 7 day Ranitidine & 7 day Omeprazole & 7 day PPSBT & 28 day PPSBT & 28 day Placebo \\
\hline Non-Responders & $20 \%(n=2 / 10)$ & $34 \%(n=2 / 9)$ & $10 \%(n=1 / 10)$ & $20 \%(n=2 / 10)$ & $11.1 \%(n=1 / 9)$ & $75 \%(n=6 / 8)$ \\
\hline Responders & $80 \%(n=8 / 10)$ & $66 \%(n=7 / 9)$ & $90 \%(n=9 / 10)$ & $80 \%(n=8 / 10)$ & $88.9 \%(n=8 / 9)$ & $25 \%(n=2 / 8)$ \\
\hline
\end{tabular}

Omperazole 20 mg bid; Ranitidine $150 \mathrm{mg}$ bid; Antacids $30 \mathrm{ml}$ qid (400 mg AlOH$/ 200 \mathrm{mg} \mathrm{MgOH} / 10 \mathrm{ml}$ ); PPSBT $1.5 \mathrm{gram}$ bid

\section{PERCENT COMPARATIVE HEARTBURN RELIEF EROSIVE GERD IN 7 DAY \& 28 DAYS}

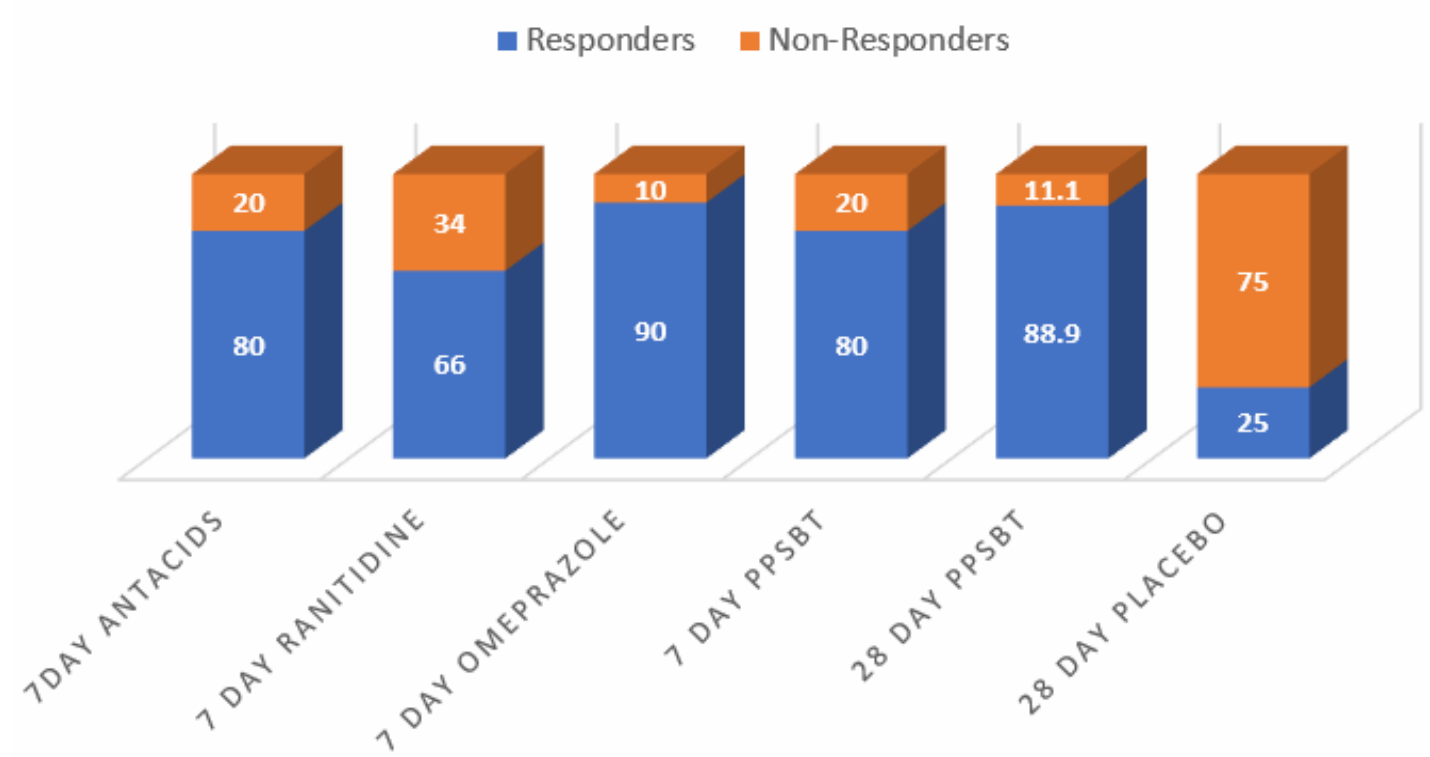

Figure 2: Percent comparative relief of heartburn in 7 days and 28 days All interventions except placebo were associated with heartburn relief that was largely comparable. 
Table 4: Comparative Healing of Erosive GERD in 7 days and 28 days.

\begin{tabular}{|l|l|l|l|l|l|l|}
\hline Intervention & 7 day Antacids & $\begin{array}{l}7 \text { day } \\
\text { Ranitidine }\end{array}$ & $\begin{array}{l}7 \text { day } \\
\text { Omeprazole }\end{array}$ & 7 day PPSBT & 28 day PPSBT & 28 day Placebo \\
\hline Partial Healing & $10 \%(n=1 / 10)$ & $11 \%(n=1 / 9)$ & $10 \%(n=1 / 10)$ & $20 \%(n=2 / 10)$ & $* 11.1 \%(n=1 / 9)$ & $* 81.2 \%(n=6 / 8)$ \\
\hline Complete Healing & $0 \%(n=0 / 10)$ & $0 \%(n=0 / 9)$ & $30 \%(n=3 / 10)$ & $80 \%(n=8 / 10)$ & $88.9 \%(n=8 / 9)$ & $18.8 \%(n=2 / 8)$ \\
\hline
\end{tabular}

*Means no healing observed; Omperazole 20 mg bid; Ranitidine $150 \mathrm{mg}$ bid; Antacids $30 \mathrm{ml}$ qid $(400 \mathrm{mg} \mathrm{AlOH} / 400 \mathrm{mg}$ $\left.\mathrm{MgOH}_{2} / 10 \mathrm{ml}\right)$; PPSBT 1.5 gram bid

Table 5: Ratio of Healing to Relief in Erosive GERD in 7 days and 28 days.

\begin{tabular}{|l|l|l|l|l|l|}
\hline Intervention & 7 day Antacids & 7 day Ranitidine & 7 day Omeprazole & 7 day PPSBT & 28 day PPSBT \\
\hline Overall Healing & $10 \%(n=1 / 10)$ & $1 \%(n=1 / 9)$ & $40 \%(n=4 / 10)$ & $100 \%(n=10 / 10)$ & $88.9 \%(n=8 / 9)$ \\
\hline Overall Relief & $80 \%(n=8 / 10)$ & $66 \%(n=7 / 9)$ & $90 \%(n=9 / 10)$ & $80 \%(n=8 / 10)$ & $88.9 \%(n=8 / 9)$ \\
\hline Ratio H/R & 0.125 & 0.167 & 0.444 & 1.25 & 1.0 \\
\hline
\end{tabular}

Omperazole 20 mg bid; Ranitidine 150 mg bid; Antacids $30 \mathrm{ml}$ qid (400 mg AlOH

\section{PERCENT COMPARATIVE HEALING RATE IN EROSIVE GERD \\ IN 7 DAYS \& 28 DAYS}

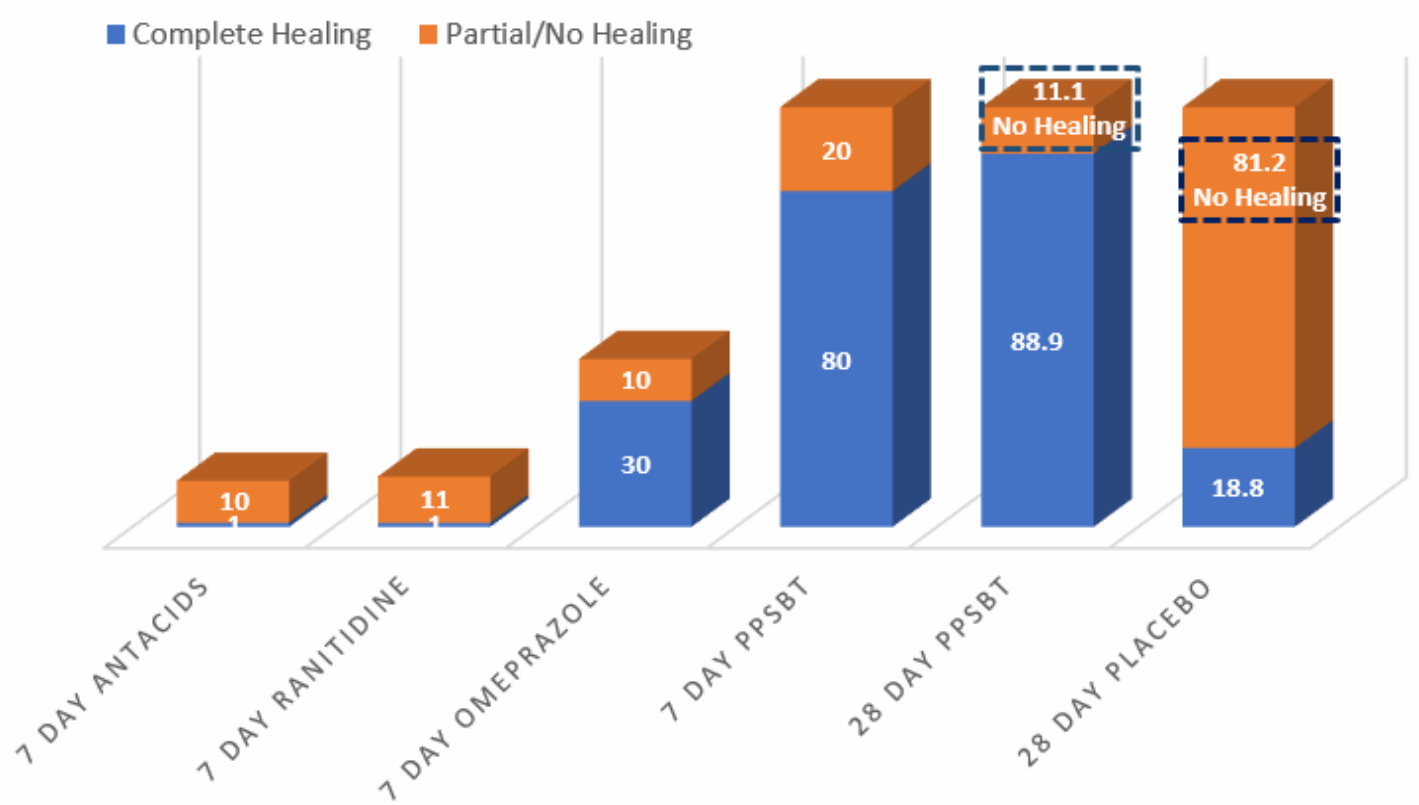

Figure 3: Percent comparative healing rate of erosive GERD in 7 days \& 28 days $\ln 7$ days only PPSBT associated with substantial healing. After 28 days PPSBT healing rate improved some. However nearly $90 \%$ of healing rate to be achieved by PPSBT occurred within the first 7 days.

2 shows that symptomatic relief with PPSBT in 7 days (80\%) was comparable to that observed in eGERD patients on omeprazole $(90 \%)$, ranitidine $(66 \%)$ and antacids (80\%).

Figure 2 also illustrates an interesting observation that, in 7 days, symptomatic relief from PPSBT (80\%) is nearly $90 \%$ of symptomatic relief achieved by PPSBT in 28 days of PPSBT (88.9\%). In other words the mechanisms used by PPSBT to achieve symptomatic relief seem to be established early, that is within the first 7 days of therapy. Table 4 shows endoscopic healing using the five interventions, placebo, antacids, ranitidine, omeprazole and PPSBT. Over 28 days healing of erosive GERD in patient using placebo was $19 \%$. Within 7 days, despite relatively high symptomatic relief, healing of
eGERD in patients using antacids $(0 \%)$, ranitidine $(0 \%)$ and omeprazole (30\%) was low, while healing in patients using PPSBT was $80 \%$. Again it is observed that the mechanism underlying healing with PPSBT is likely substantially operative with 7 days, given that over $90 \%$ of healing achieved by 28 days using PPSBT occurs within the first 7 days.

Figure 3 illustrates the extent of endoscopic healing in erosive GERD using all five interventions.

Table 5 explores the point that 7 day symptomatic relief from antacids, ranitidine and omeprazole is incongruent with healing by these intervention over the same period of time.

Looking at healing as a function of relief, Figure 4 


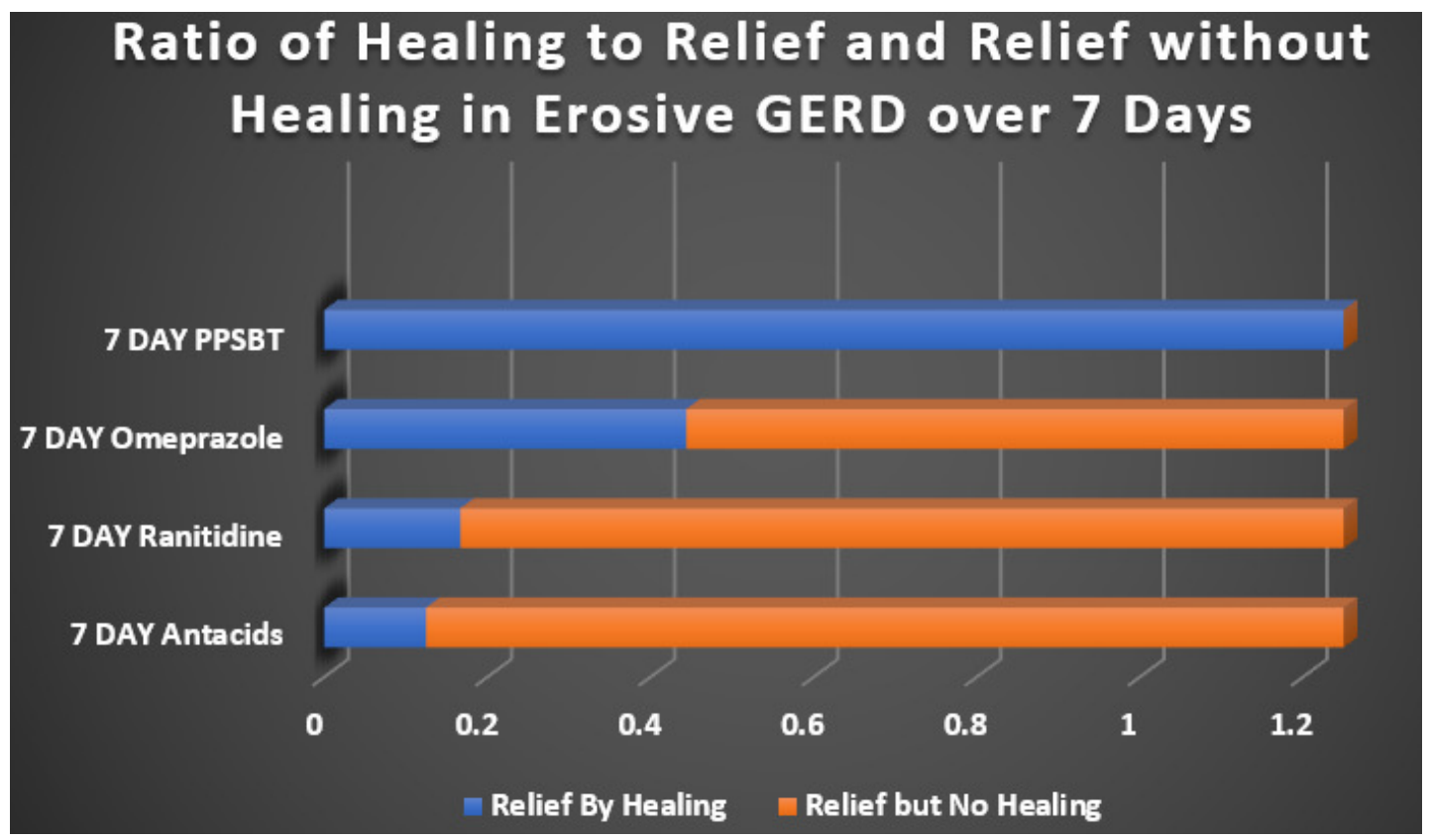

Figure 4: Ratio of Healing to Heartburn Relief in 7 days. The ratio of overall healing to overall relief in patients with erosive GERD taking omperazole $20 \mathrm{mg}$ bid, ranitidine $150 \mathrm{mg}$ bid, antacids $30 \mathrm{ml}$ qid (400 mg AlOH $/ 400 \mathrm{mg} \mathrm{MgOH} / 10 \mathrm{ml})$ and PPSBT $1.5 \mathrm{gram}$ bid over 7 days. The healing/relief ratios from interventions were normalized to the healing/relief ratio observed with 7 day PPBST to approximate the proportion of those having relief without healing.

\section{Percent Responders/Non-Reponders to PPSBT \& Placebo in Undifferentiated NERD at end of 28 days}

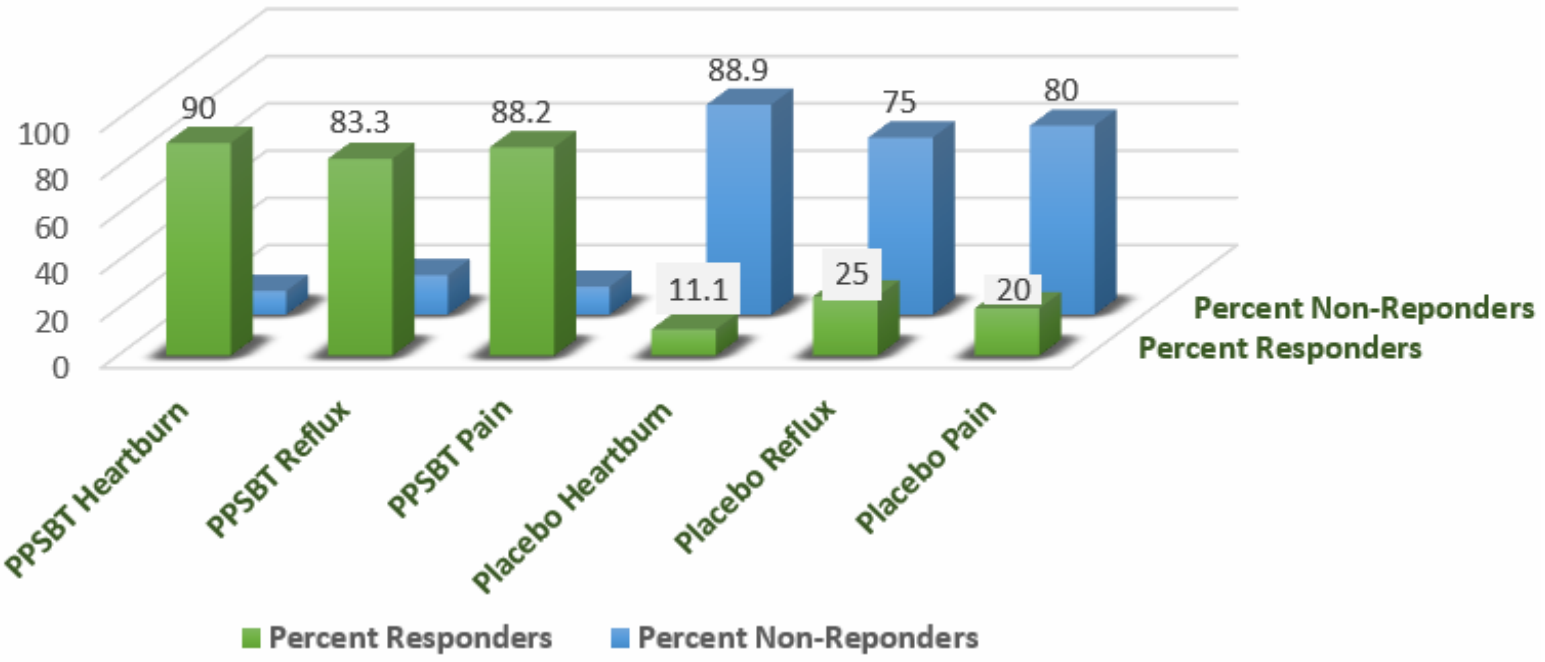

Figure 5: Percent responsive \& non-responsive in undifferentiated NERD GERD in 28 days In this cohort of undifferentiated NERD patients (containing functional heartburn, esophageal hypersensitivity and classic NERD), PPSBT was associated with relief of heartburn, reflux sensation and retrosternal pain.

illustrates a near 1 to 1 ratio of high symptomatic relief from PPSBT to high incidence of PPSBT healing in 7 days; the opposite is observed for antacids, ranitidine and omeprazole.

In patients taking antacids, ranitidine and omeprazole, the proportion of those receiving relief without substantial healing is high. This implies that, contrary to clinical guidelines $[1,3,4]$, interventions whose sole mechanism of action centered on elevating $\mathrm{pH}$ is not sufficient to reverse mucosal inflammation within 7 days.
This implication suggests that caustic acid alone may not be the sole cause of the mucosal reaction to reflux. As a point covered in recent literature $[36,50,51,134]$. bile acids and serine proteases (trpysin, chymotrypsin) are co-equal irritants within gastric refluxate.

PPSBT does not alter gastric $\mathrm{pH}$. It coats the mucus gel, biophysically altering its properties to minimize access of acid to neurofibers with switched-on voltage-gated nociceptors. Symptomatic relief from PPSBT within the first 7 days suggests that limiting biophysical 
access of acid to the mucosa is a legitimate mechanism of action.

Also obvious from Figure 3 and Figure 4, is that the relative absence of mucosal healing in the setting of substantial relief suggests that acid-controlling therapies may require therapeutic actions of supplementary interventions to address non-acid irritants of esophageal mucosa.

The incidence of substantial healing in the setting of significant relief in patients using PPSBT during the first 7 days suggests PPSBT use to supplement acid-controlling therapies. There was $30 \%$ healing with omeprazole in 7 days. This may speak to reported anti-inflammatory effect of PPI's in patients with GERD $[46,135]$. Clearly, in this trial, any direct anti-inflammatory effect of omeprazole was 2.6 fold less effective than that observed with PPSBT, achieved solely by PPSBT's ability to physically deny irritants access to the esophageal mucosa.

\section{PPSBT in NERD}

There are no specific management guidelines for NERD. The Vevey NERD Consensus Group, excludes functional heartburn and reflux hypersensity from the NERD, and recommend use of acid-controlling therapies, PPI's, H2RA and antacids where useful [136]. However, clearly the similarity of histomorphology, transmembrane resistance, and immunoreactions in sub-cohorts of NERD patients [22-24] suggest that esophageal exposure to gastric refluxate has a decisive role in symptoms regardless of sub-type of NERD present. Thus for all sub-types of NERD, physical exclusion of refluxate (or of dissolved irritants) is key. These patients too, are vulnerable to the irritant contents of gastric refluxate.

As shown in Table 6, for patients with NERD, PPSBT was found to be more effective than placebo against three types of symptoms -heartburn, reflux sensation and retrosternal discomfort or pain.

Figure 5 illustrates the data listed in Table 6. Over

Table 6: Symptomatic Outcome in Undifferentiated NERD in 28 Days.

\begin{tabular}{|c|c|c|c|c|c|c|}
\hline \multirow{2}{*}{\begin{tabular}{|l|} 
Intervention \\
NERD \\
Symptoms \\
\end{tabular}} & \multicolumn{3}{|l|}{ PPSBT } & \multicolumn{3}{|l|}{ Placebo } \\
\hline & Heartburn & Reflux & Pain & Heartburn & Reflux & Pain \\
\hline \% Responsive & $90 \%(n=18 / 20)$ & $83.3 \%(n=15 / 18)$ & $88.2 \%(n=15 / 17)$ & $11.1 \%(n=2 / 18)$ & $25 \%(n=4 / 16)$ & $20 \%(n=3 / 15)$ \\
\hline $\begin{array}{l}\% \text { Non- } \\
\text { responsive }\end{array}$ & $10 \%(n=18 / 20)$ & $16.7 \%(n=3 / 18)$ & $11.8 \%(n=2 / 17)$ & $88.9 \%(n=16 / 18)$ & $75 \%(n=12 / 16)$ & $80 \%(n=12 / 15)$ \\
\hline
\end{tabular}

Table 7: Composite Symptomatic Relief \& Antacid Use in Undifferentiated NERD over 28 Days.

\begin{tabular}{|l|l|l|l|}
\hline & Composite Responders & Composite Non-Responders & Percent Antacid Use \\
\hline PPSBT & $87.3(n=48$ of 55) & $12.7(n=7$ of 55$)$ & $12.5(n=20$ of 160 btls $)$ \\
\hline Placebo & $18.4(n=9$ of 49$)$ & $81.6(n=40$ of 49$)$ & $75.7(n=109$ of 144 btls $)$ \\
\hline
\end{tabular}

\section{Composite Symptom Response \& Antacid Use in Undifferentiated NERD over 28 days}

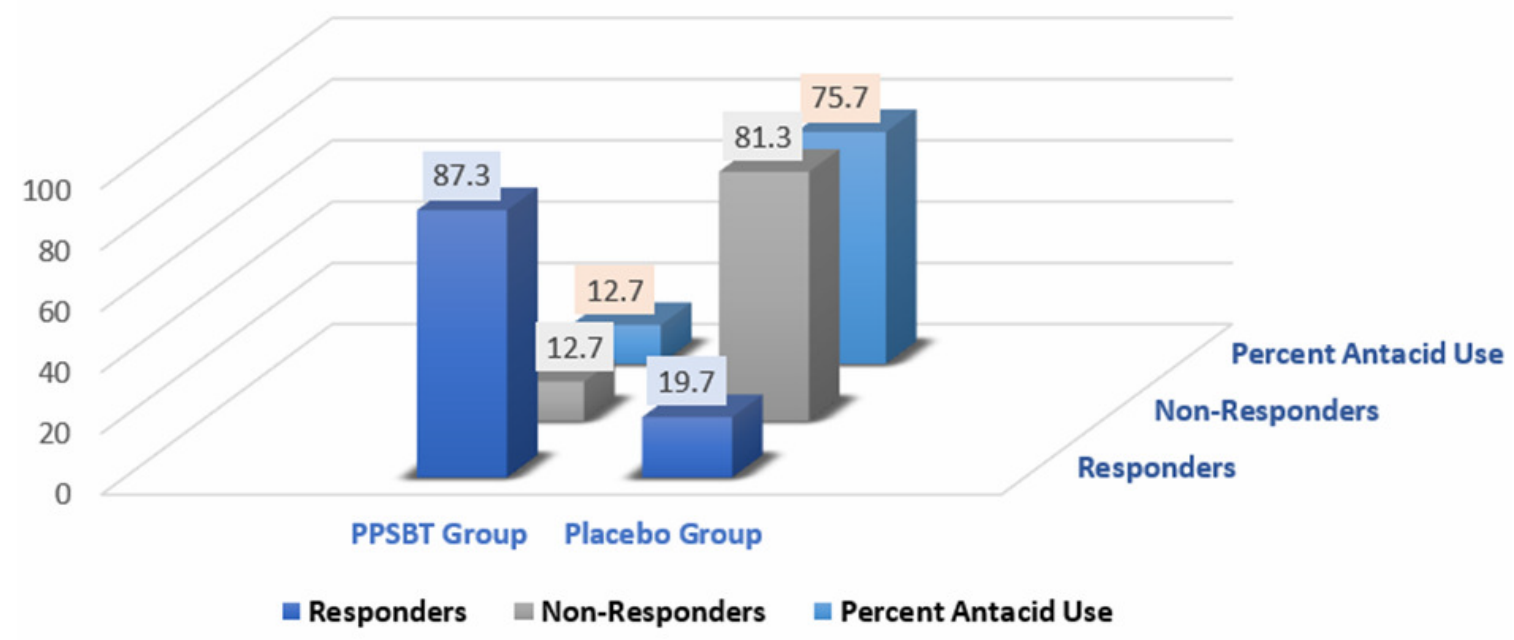

Figure 6: Composite Symptomatic response \& antacid use in undifferentiated NERD in 28 days In this cohort of undifferentiated NERD patients (functional heartburn, esophageal hypersensitivity and classic NERD), PPSBT was associated with significant relief with minimal use of antacids. 
28 days, $90 \%$ with heartburn, $83 \%$ with reflux sensation $\mathrm{nf} 88 \%$ with retrosternal discomfort responded to PPSBT, while the opposite was true for those using placebo.

Table 7 shows the composite of overall responders and non-responders. There was minimal use of antacids in NERD patients using PPSBT. However, as seen in Figure 6 , for NERD patients using placebo, antacid use was 6 fold greater.

\section{PPSBT versus other sucralfate preparations for eGERD and NERD}

Patients with either erosive GERD or NERD appear to respond to PPSBT. There have been valid studies reported in the past using other sucralfate preparations for eGERD and NERD.

Vermeijden, et al. [8] was the only sucralfate study for eGERD that qualified for inclusion in a Cochrane meta-analysis report and could be compared to PPSBT for efficacy in healing [133]. Data on symptomatic control was somewhat challenging due to difference in methodology to quantify symptomatic effect. However the presence or absence of endoscopic erosions can be compared. Vermeijden, et al. [8] observed that in 56 days, 4 grams daily of standard sucralfate (polymerized by gastric acid) achieved a healing rate of $68 \%$. For PPSBT required 7 days using 3 grams daily to achieve $80 \%$ complete healing in patients with erosive GERD. Over 56 days, 224 grams of sucralfate was used to heal 68\%; over 7 days, 21 grams of PPSBT was used to heal $80 \%$ of individuals with erosive GERD. By days and dosage of sucralfate required, PPSBT used $1 / 8$ the time and $10 \%$ of the dose to achieve healing rate that was better than that reported by Vermeijden, et al. [8].

Simon, et al. [5] used sucralfate gel to treat NERD patients and found it to be effective. Since the method of assessing relief differed, a valid comparison for symptomatic relief using sucralfate gel was not possible with symptomatic relief using PPSBT. Still it suffice to say that it took Simo, et al. 42 days to report $71 \%$ symptomatic relief in NERD patient using 2 grams of sucralfate daily. It took 28 days for $87 \%$ of NERD patients to have symptomatic relief using 3 grams of sucralfate daily. Whether it would have taken less time with PPSBT is unknowable since a 7 day, 14 day or 21 day study was not performed.

\section{Conclusion}

Whether that is a role for PPBST in the management of GERD and NERD will likely be answered one clinician at a time. From published data there appear to be some utility. From the literature, it appears that the loss of mucosal integrity is the determinative pathology in GERD and NERD and effective therapeutic interventions that address mucosal integrity would be a welcomed option.
Gastric acid permeation from the lumen to the esophageal epithelium is broadly accepted [43]. Less known but clearly affirmed is the involvement of water soluble bile acids and serine proteases that cause mucosal reactions [36,38,41,49,51] which some believe proceed to Barrett's esophagus [137] and to esophageal adenocarcinoma $[138,139]$.

All three irritants - acid, bile acids and proteases - give rise to cytokine-driven inflammatory changes within the esophageal mucosa $[29,140,141]$. Acid-controlling therapies alone are not adequate for the clinical challenge.

The existential deterrent to mucosal injury by gastric refluxate is the biophysical integrity of the mucus gel. Dose-dependent engagement of pre-polymerized sucralfate with mucin [86-88] physically fortifies structural characteristics of the mucus gel, a fortification that results in at least five specific effects.

There first effect is reduction of acid permeation through the mucus gel [94]; a second effect is hindrance of water-soluble bile acids to infiltrate mucus gel by sucralfate-associated enhancement of mucin hydrophobicity $[93,96]$; a third effect is the resilience of sucralfate- fortified mucin against degradation by serine proteases thus disallowing access to apical epithelium $[97,99,142]$ to further inflammation throughout squamous epithelium. A fourth effect is reduction of cationic penetration through the mucus gel [95] thereby starving the ion flux required to keep voltage-gated nociceptors switched on; the result of which is afferent neurofibres are switched off. The fifth specific effect is the least understood, but perhaps the most important. It involves sucralfate enhanced mucus gel viscosity [93] that is biophysically translated into intra-cellular signaling. It is the author's view that transduction of biophysicial 'stoutness' to intracellular signalaing is responsible for all near immediate ultrastructural, histological and humoral tissue changes, observed in the early days by Tarnawski, et al. $[100,101]$. Dose-dependent biophysical corpulence of sucralfate-engaged mucin result in an increased secretion of mucin, enhanced luminal expression of prostaglandin E2 and bicarbonate and simultaneous regenerative changes in the epithelium nearest the area of greatest sucralfate- mucin engagement.

The transduction of biophysical 'stoutness' into intracellular signaling is likely through agency of transmembrane mucins [112] which stud the apical surface of the epithelium and is interwoven with extra-cellular mucin. Biophysical transduction of enhanced mucin gel integrity leads to anti-inflammatory and cytoprotective actions of epithelial cells accessorized by apical transmembrane mucin. This transduction of sucralfate-enhanced mucin biophysics possibly aided by the complexation of globet-drived trefoil factors with the von Wildebrand factor segment of the transmembrane mucin [117] as optimized trefoil complexation with transmembran mucin modulates intracel- 
lular signaling that controls apoptosis, cell differientiation and pro-inflammatory and anti-inflammatory processes through the epithelium into the lamina propria. The cytsolic sections of transmembrane mucin are known to translocate from the apical epithelial membrane to the nucleus [112] to participate in control of cytoprotective functions. This fifth effect of sucralfate-mucin engagement may be considered a viscosity associated optimization of trefoil factor-transmembrane mucin cross-linkage that translates into intra-cellular signaling to drive reversal of pro-inflammatory mucosal damage $[113,114]$.

These five effects likely explain the efficacy of pre-polymerized sucralfate in erosive and non-erosive GERD, a role for which seems apparent.

\section{Funding}

The author received no funding for the conception, literature review and preparation of this manuscript. Randomized controlled trials cited in the report were funded by Mueller Medical International. However, the company had no role in the conductor design of trials and placed no restrictions on the curation or report of data.

\section{Conflict of Interest}

Author is an employee of the company that owns a technology which polymerizes sucralfate.

\section{Declaration of Conflicting Interests}

Author is employed by company that owns technology that pre-polymerizes sucralfate.

\section{References}

1. Katz PO, Gerson LB, Vela MF (2013) Guidelines for the diagnosis and management of gastroesophageal reflux disease. Am J Gastroenterol 108: 308-328.

2. Huerta-Iga F, Bielsa-Fernandez MV, Remes-Troche JM, et al. (2016) Revista de Gastroenterol Mex 81: 208-222.

3. Fock KM, Talley NJ, Fass R, Goh KL, Katelaris $P$, et al. (2008) Asia-Pacific concensus on the management of gastroesophageal reflux disease: Update. J Gastroenterol Hepatol 23: 8-22.

4. Armstrong D, Marshall JK, Chiba N, Enns R, Fallone CA, et al. (2005) Canadian Consensus Conference on the management of gastroesophageal reflux disease in adults - update 2004. Can J Gastroenterol 19: 15-35.

5. Simon B, Ravelli GP, Goffin H (1996) Sucralfate gel versus placebo in patients with non-erosive gastro-oesophageal reflux disease. Aliment Pharmacol Ther 10: 441-446.

6. Hardy JG, Hooper G, Ravelli GP, Steed KP, Wilding IR (1993) A comparison of the gastric retention of a sucralfate gel and a sucralfate suspension. Eur J Pharmacol Biopharmacol 39: 70-74.

7. Vaira D, Corbelli C, Brunetti G, Menegatti M, Levorato M, et al. (1993) Gastric retention of sucralfate gel and suspension in upper gastrointerstinal diseases. Aliment Pharmacol Ther 7: 531-535.
8. Vermeijden JR, Tytgat GN, Schotborgh RH, Dekker W, vd Boomgaard DM, et al. (1992) Combination therapy of sucralfate and ranitidine, compared with sucralfate monotherapy, in patients with peptic reflux esophagitis. Scand J Gastroenterol 27: 81-84.

9. Nagashima R (1981) Development and characteristics of sucralfate. J Clin Gastroenterol 3: 103-110.

10. Oshea S. Office of Combination Products. Request for Designation Sucralfate $\mathrm{HCl}$ Topical Paste.

11. McCullough RW (2014) Mucosa-Centric Clinical Effects of High Potency Sucralfate: 28 Day 83\% Resolution of Undifferentiated Dyspepsia, 28 Day 83\% Reversal of Sign \& Symptoms of Co-Morbid IBS and 1 Week $80 \%$ Healing of GERD. Gastroenterol 146: S-263.

12. Bennett JR. What is physiological gastroesophageal reflux?.

13. Dent J, Dodds WJ, Hogan WJ, Toouli J (1988) Factors that influence induction of gastroesophageal reflux in normal human subjects. Dig Dis Sci 33: 270-275.

14. J Dent, W J Dodds, R H Friedman, T Sekiguchi, W J Hogan, et al. (1980) Mechanism of gastroesophageal reflux in recumbent asymptomatic human subjects. J Clin Invest 65: 256-267.

15. Dodds WJ, Dent J, Hogan WJ, Helm JF, Hauser R, et al. (1982) Mechanisms of gastroesophageal reflux in patients with reflux esophagitis. N Engl J Med 307: 1547-1552.

16. Drossman DA (2016) Functional gastrointestinal disorders: History, pathophysiology, clinical features and Rome IV. Gastroenterol 150: 1262-1279.

17. Qasim Aziz, Ronnie Fass, C Prakash Gyawali, Hiroto Miwa, John E Pandolfino, et al. (2016) Esophageal disorders. Gastroenterol 150: 1368-1379.

18. Yamasaki T, Fass R (2017) Reflux hypersensitivity: A new functional esophageal disorder. J Neuorogastroenterol Motil 23: 495-503.

19. Woodland P, Al-Zinaty M, Yazaki E, Sifrim D (2013) In vivo evaluation of acid-induced changes in oesphageal mucosa integrity and sensitivity in non-erosive reflux disease. Gut 62: 1256-1261.

20. Farre $R$ (2013) Pathophysiology of gastro-esphageal reflux disease: A role for mucosa integrity? Neurogastroenterol Motil 25: 783-799.

21. Weijenborg PW, Smout AJ, Verseijden C, van Veen HA, Verheij J, et al. (2004) Hypersensitivity to acid is associated with impaired esophageal mucosal integrity in patients with gastroesophageal reflux disease with and without espohagitis. Am J Physiol Gastrointest Liver Physiol 307: 323-329.

22. Caviglia R, Ribolsi M, Maggiano N, Gabbrielli AM, Emerenziani S, et al. (2005) Dilated intercellular spaces of esophageal epithelium in non-erosive reflux disease patient $s$ with physiological esophageal acid exposure. Am J Gastroenterol 100: 543-548.

23. Kandulski A, Jechorek D, Caro C, Weigt J, Wex T, et al. (2013) Histomorphological differentiation of non-erosive reflux disease and functional heartburn in patients with PPI-refactory heartburn. Aliment Pharmacol Ther 38: 643651.

24. Kanazawa $Y$, Isomoto $H$, Wen CY, Wang AP, Saenko VA, et al. (2003) Impact of endoscopically minimal involvement on IL-8 mRNA expression in esophageal mucosa of patients with non-erosive reflux disease. World J Gastroenterol 9: 2801-2804. 
25. Fitzgerald RC, Onwuegbusi BA, Bajaj-Elliott M, Saeed IT, Burnham WR, et al. (2002) Diversity in the oesophageal phenotypic response to gastro-oesophageal reflux: immunological determinants. Gut 50: 451-459.

26. Yue Yu, Xiping Ding, Qiaomin Wang, Li Xie, Wen Hu, et al. (2011) Alterations of mast cells in the esophageal mucosa of the patients with non-erosive reflux disease. Gastroenterol Res 4: 70-75.

27. Harnett KM, Rieder F, Behar J, Biancani P (2010) Viewpoints on acid-induce inflammatory mediators in esophageal mucosa. J Neurogastroenterol Moti 16: 374-388.

28. Isomoto $\mathrm{H}$, Wang A, Mizuta $\mathrm{Y}$, Akazawa $\mathrm{Y}$, Ohba K, et al. (2003) Elevated levels of chemokines in esophageal mucosa of patients with reflux esophagitis. Am J Gastroenterol 98: 551-556.

29. Souza RF, Huo X, Mittal V, Schuler CM, Carmack SW, et al. (2009) Gastroesophageal reflux might cause esophagitis through a cytokine-mediated mechanism rather than caustic acid injury. Gastroenterol 137: 1776-1784.

30. Farré R, van Malenstein H, De Vos R, Geboes K, Depoortere I, et al. (2008) Short exposure of oesophageal mucosa to bile acids, both in acidic and weakly acidic conditions, can impair mucosal integrity and provoke dilated intercellular spaces. Gut 57: 1366-1374.

31. Brock C, Gregersen H, Gyawali P, Lottrup C, Furnari M, et al. (2016) The sensory system of the esophagus- what do we know? Ann NY Acad Sci 1380: 91-103.

32. Van Hoeij FB, Weijenborg PW, van den Berg MA, René M J G J van den Wijngaard, J Verheij, et al. (2016) Mucosal integrity and sensitivity to acid in the proximal esophagus in patients with gastroesophageal reflux disease. Am J Physiol Gastrointest Liver Physiol 311: 117-122.

33. Holtzer P (2015) Acid-sensing ion channels in gastrointestinal function. Neuropharmacol 94: 72-79.

34. Holtzer P (2011) Transient receptor (TRP) channels as drug targets for diseases of the digestive system. Pharmcol Therap 131: 142-170.

35. Holtzer P (2009) Acid-sensitive ion channels and receptors. Handb Ex Pharmacol 194: 283-332.

36. Gotley DC, Morgan AP, Ball D, RW Owen, MJ Cooper (1991) Composition of gastro-oesophagel refluxate. Gut 32: 1093-1099.

37. Hofmann AF, Mysels KJ (1992) Bile solubility and precipitation in vitro and in vivo: the role of conjugation, $\mathrm{pH}$, and Ca2+ ions. J Lipid Res 33: 617-626.

38. Nehra D, Howell P, Williams CP, J Beynon (1999) Toxic bile acids in gastro-oesophageal reflux disease: influence of gastric acidity. Gut 44: 598-602.

39. Hershcovici T, Jha LK, Cui H, J Powers, R Fass (2011) Night-time intra-oesophageal bile and acid: a comparison between gastro- esophageal reflux disease patients who failed and those who were treated successfully with a proton pump inhibitor. Aliment Pharmacol Ther 33: 837-844.

40. Ghatak S, Reveiller M, Toia L, Andrei I Ivanov, Zhongren Zhou, et al. (2016) Bile salts at low pH cause dilation of intercellular spaces in in vitro stratified primary esophageal cells, possibly by modulating Wnt signaling. J Gastrointest Surg 20: 500-509.

41. Chen $x$, Oshima T, Shan J, Hirokazu Fukui, Jiro Watari, et al. (2012) Bile salts dirupt human esophageal squamous epithelial barrier function by modulating tight junction proteins. Am J Physiol Gastrointest Liver Physiol 303: 199-208.
42. Li WT, Luo QQ, Chen X, Bo Wang, Xiu-Juan Yan, et al. (2019) Bile acids induce visceral hypersensitivity via mucosal mast cell-t0-nociceptor signaling that involves the farnesoid $X$ receptor/nerve growth factor/transient receptor potential vanilloid 1 axis. FASEB J 33: 2435-2450.

43. Vaezi MF, Richter JE (1996) Role of acid and duodenogastroesophageal reflux in gastroesophageal reflux disease. Gastroenterol 111: 1192-1199.

44. Tack J, Koek G, Demedts I, D Sifrim, J Janssens (2004) Gastroesophageal reflux disease poorly responsive to single-dose proton pump inhibitors in patients without Barrett's esophagus: acid reflux, bile reflux, or both? Am J Gastroenterol 99: 981-988.

45. Fitzgerald RC, Abdalla S, Onwuegbusi BA, P Sirieix, I T Saeed, et al. (2002) Inflammatory gradient in Barrett's oesophagus: implications for disease complications. Gut 51: 316-322.

46. Huo X, Zhang X, Yu C, Qiuyang Zhang, Edaire Cheng, et al. (2004) In oesophageal squamous cells exposed to acidic bile salt medium, omeprazole inhibits IL-8 expression through effects on nuclear factor kB and activator protein-1. Gut 63: 1042-1052.

47. Kim JJ, Kim N, Choi YJ, Joo Sung Kim, Hyun Chae Jung (2016) Increased TRPV1 and PAR2 mRNA expression levels are associated only with the esophageal reflux symptoms but not with extrasophageal reflux symptoms. Mediine (Baltimore) 95: 4387.

48. Yoshida N, Kamada K, Tomatsuri N, Takahiro Suzuki, Hiroshi Ichikawa, et al. (2011) Non-erosive reflux disease and neurogenic inflammation: Assocation of circulating substance $P$ and nerve growth factor levels with heartburn symptoms. Gastroenterol 140: S-621.

49. Shan J, Oshima T, Chen X, Hirokazu Fukui, Jiro Watari, et al. (2012) Trypsin impaired epithelial barrier function and induced IL-8 secration through basolateral PAR-2: a lesson from a stratified squamous epithelial model. Am J Physiol Gastrointest Liver Physiol 303: 1105-1112.

50. Bjorkman EV, Edebo A, Oltean M, Casselbrant A (2013) Esophageal barrier function and tight junction expression in healthy subjects and patients with gastroesophageal reflux disease: functionality of esophageal mucosa exposed to bile salt and trypsin in vitro. Scand J Gastroenterol 48: 1118-1126.

51. Kandulski A, Wex T, Monkemuller K, Doerthe Kuester, Lucia C Fry, et al. (2010) Proteinase-activated receptor-2 in the pathogenesis of gastroesophageal reflux disease. Am J Gastroenterol 105: 1034-1043.

52. Hunter $J(1772)$ On the digestion of the Stomach after death. Philosh Trans 62: 447.

53. Pavy FW (1863) On the Immunity enjoyed by the Stomach from being digested by its own secretion during life. Boston Med Surg J 68: 514-516.

54. Schiff M (1898) Autodigestion of the Stomach after death and during life. Beitr Physiol 4: 405.

55. de Klug F (1902) Pourquoi les ferments protéolytiques ne digèrent-ils pas l'estomac et l'intestin sur le vivant? Arch Internat Physiol 5: 297.

56. Irvine JC, Hynd A. Synthetical Aminoglucosides derived from d-glucosamine (Series). J Chem Soc Trans 1911; 99:250; J Chem Soc Trans 1912: 101:1128 and J. Chem Soc Trans 1913; 103:41-56.

57. Levine PA, Lopez-Suarez J (1918) Mucins and Mucoids. J Biol Chem 36: 105-126. 
58. Whitlow JE (1920) The protective role of gastric mucus against the proteolytic action of gastric secretion. Master's Thesis. Loyola University Medical School.

59. Bradley HC, Hodges M (1934) The effect of mucin and mucinoids on peptic digestion. J Lab Clin Med 20: 165-169.

60. Miller CO, Dunbar J (1933) Change in viscosity of mucin with pH. Proc Soc Exper Biol Med 30: 627.

61. Atkinson AJ (1932) Gastric mucin in the treatment of peptic ulcer. JAMA 98: 1153-1156.

62. Babkin BP, Komarov SA (1932) The influence of gastric mucus on peptic digestion. Can Med Assoc J 27: 463-469.

63. Hollander F, Stein J Laubeer FU (1946) The consistency, opacity and columnar cell content of gastric mucus secreted under the influence of several mild irritants. Gastroenterology 6: 576-595.

64. Hollander F, Sonnenblick BP, Sober HA (1947) Experimental impairment of the gastric mucous barrier in dogs. Journal of National Cancer Institution 7: 361-364.

65. Hollandeer F (1950) Secretion of gastric mucus in health and disease, in Postgraduate Gastroenterology. Bockus HL editor. Philidelphia, WB Saunders Company 39-52.

66. Janowitz HD, Hollander F (1951) Some properties of cellfree gastric mucus. Fed Proc 10: 70.

67. Levey S, Sheinfeld S (1954) The inhibition of the proteolytic action of pepsin by sulfate containing polysaccharides. Gastroenterology 27: 625-628.

68. Anderson W, Watt J (1959) Inhibition of peptic activity, protection against histamine ulceration in the guinea pig and combination with gastric mucin by an algal polyanion. $J$ Pharm Pharmacal 11: 318.

69. Bianchi RG, Cook DL (1964) Anti peptic and anti ulcerogenic properties of a synthetic sulfated polysaccharide (SN263). Gastroenterology 47: 409-414.

70. Cook DL, Eich S, Cammarata PS (1963) Comparative pharmacology and chemistry of synthetic sulfated polysaccharides. Arch Int Pharmacodyn Ther 144: 1-19.

71. Cayer D, Raffin JM (1967) Effect of Depepsin (amylopectin sulfate) in the treatment of peptic ulcer. Ann NY AcadSci 140: 744-746.

72. Ishimori A (1995) History of the development of sucralfate. Chapter 4: 35-44.

73. Ishimori A (1971) Mechanism of the antipeptic action of anionic carbohydrate and its clinical application for the treatment of peptic ulcer. Tohoku J Exp Med 103: 141-157.

74. Yamagata S, Ishimori A, Sato $H$, Okabe $H$, Ishihara $K$ (1973) Clinical evaluation of pharmacotherapy for peptic ulcer with antipepsin agents by double blind technique multicenter clinical study. Tohoku J Exp Med 110: 377-404.

75. Nitta Y, Masaya K, Kawa-saki-shi N (1969) Dissacharidepolysulfatealuminium compound and method.

76. (1982) US Food and Drug Administration. Carafate Sucralfate.

77. (1991) US Food and Drug Administration. Carafate Sucralfate Suspension.

78. (2019) Drugs.com. Sucralfate.

79. Ishimori A (1981) Safety experience with sucralfate in Japan. J ClinGastroenterol 3: 169-173.

80. Nakazawa S, Nagashima R, Samloff IM (1981) Selective binding of sucralfate to gastric ulcer in man. Dig Dis Sci N S 26: $297-300$.

81. Sasaki H, Hinohara Y, Tsunoda Y, Nagashima R (1983) Binding of sucralfate to duodenal ulcer in man. Scand $\mathrm{J}$ Gastroenterol Suppl 83: 13-14.

82. Nagashima R (1981) Mechanisms of action of sucralfate. J Clin Gastroenterol 3: 117-127.

83. Kashimura K, Ozawa K (1999) Sucralfate Preparations. US Patent 5: 968,906.

84. McGaughey GB, Gagne M, Rappe AK (1998) Pi-stacking interacitons alive and well in proteins. J Biol Chem 273: 15458-15463.

85. Mathews DR, Dahl NG (1995) Safety of sucralfate: From basic science to the bedside, edited by Daniel Hollander and G. N. J. Tytgat. Plenum Press, New York.

86. Morris GP (1995) Binding of sucralfate to mucosal surface. In Sucralfate: From basic science to the bedside. Edited by Daniel Hollander and GNJ Tygat Plenum Press, New York.

87. Cohen MM, Bowdler R, Gervais P, Morris GP, Wang HR (1989) Sucralfate protection of human gastric mucosa against acute ethanol injury. Gastroenterol 96: 292-298.

88. Tasman-Jones C, Morrison G, Thomsen L, vanDerwee $M$ (1989) Sucralfate interactions with gastric mucus. Am J Med 86: 5-9.

89. Masuelli L, Tumino G, Turriziani M, Modesti A, Bei R (2010) Topical use of sucralfate in epithelial wound healing: Clinical evidence of molecular mechanisms of action. Recent Pat Inflamm Allergy Drug Discov 4: 25-36.

90. Konturek SJ, Brozozowski T, Bielanski W, Warzecha Z, Drozdowicz D (1989) Epidermal growth factor in the gastroprotective and ulcer-healing actions of sucralfate in rats. Am J Med 86: 32-37.

91. Nexo E, Poulsen SS (1987) Does epidermal growth factor play a role in the action of sucralfate? Scand J Gastroenterol Suppl 127: 45-49.

92. Hollander D, Tytgat GNJ (1995) Sucralfate: From Basic Science to the Bedside. In: Daniel Hollander, GNJ Tytgat, Plenum Press, New York.

93. Slomiany BL, Murty VL, Piotrowski J, Slomiany A (1989) Effect of antiulcer agents on the physiochemical properties of gastric mucus. Symp Soc Exp Biol 43: 179-191.

94. Slomiany BL, Laszewicz W, Murty VL, Kosmala M, Slomiany A (1985) Effect of sucralfate on the viscosity and retardation of hydrogen ion diffusion by gastric mucus glycoprotein. Comp Biochem Physiol C 82: 311-314.

95. Slomiany BL, Liu J, Slomiany A (1992) Modulation of gastric mucosal calcium channel activity by sucralfate. Biochem Int 28: 1125-1134.

96. Caspary WF (1995) Binding of bile salts by sucralfate. In: Daniel Hollander, GNJ Tygat, Sucralfate: from basic science to the bedside. Plenum Press, New York.

97. Schweitxer EJ, Bass BL, Johnson LF, Harmon JW (1985) Siucralfate prevents experimental peptic esophagitis in rabbits. Gastroenterol 88: 611-619.

98. Louw JA, Young GO, Winter TA, Marks IN (1995) Sucralfate and Helicobacter Pylori. In: Daniel Hollander, GNJ Tygat, Sucralfate: from basic science to the bedside. Plenum Press, New York.

99. Slomiany BL, Piotrowski J, Slomiany A (1992) Effect of sucralfate on the degradation of human gastric mucus by he- 
licobacter pylori protease and lipases. Am J Gastroentero 87: 595-599.

100. Tarnawski A, Hollander D, Stachura J, Mach T, Bogdal J (1987) Effect of sucralfate on the normal human gastric mucosa. Endoscopic, histologic, and ultrastructural assessment. Scand J Gastroenterol Suppl 127: 111-123.

101. Tarnawski A, Hollander D, Krause WJ, Zipser RD, Stachura J, et al. (1986) Does sucralfate affect the normal gastric mucosa? Histologic, ultrastructural and functional assessment in the rat. Gastroenterol 90: 893-905.

102. France MM, Turner JR (2017) The mucosal barrier at a glance. J Cell Sci 130: 307-314.

103. Dixon J, Struggala V, Griffin SM, Welfare MR, Dettmar PW, et al. (2001) Esophageal mucin: An adherent mucus gel barrier is absent in the normal esophagus but present in columnar-lined Barrett's esophagus. Am J Gastroenterol 96: $2575-2583$.

104. Lehr CM, Poelma FGJ, Hans E.Junginger, Josef J.Tukker (1991) An estimate of turnover time of intestinal mucus gel layer in the rat in situ loop. Intl $\mathrm{J}$ Pharmaceutics 70 : 235-240.

105. Rubinstein A, Tirosh B (1994) Mucus gel thickness and turnover in the gastrointestinal tract of the rat: response to cholinergy stimulus and implication for mucoadhesion. Pharm Res 1: 794-799.

106. Johansson MEV (2012) Fast Renewal of the Distal Colonic Mucus Layers by the Surface Goblet Cells as Measured by In Vivo Labeling of Mucin Glycoproteins. PLoS ONE 7: e41009.

107. Kararli TT (1995) Comparison of the gastrointestinal anatomy, physiology and biochemistry of humans and commonly used laboratory animals. Biopharmaceut Drug Disp 16: $351-380$

108. Powell DW (1987) lon and water transport in the intestine. In: TE Andreoli, SG Schultz, Physiology of Membrane Disorders. (2 ${ }^{\text {nd }}$ edn), Plenum, New York, 559-596.

109. Lang T, Hansson GC, Samuelsson T (2007) Gel-forming mucins appeared early in metazoan evolution. Proc Natl Acad Sci USA 104: 16209-16214.

110. Atuma C, Strugala V, Allen A, Holm L (2001) The adherent gastrointestinal mucus gel layer: thickness and physical state in vivo. Am J Physiol Gastrointest Liver Physiol 280: G922-G929.

111. Johnansson MEV, Phillipson M, Petersson J, Velcich A, Holm L, et al. (2008) The inner of the two MUC2 mucin-dependent mucus layers in colon is devoid of bacteria. Proc Natl Acad Sci USA 105: 15064-15069.

112. van Putten JP, Strijbis K (2017) Transmembrane mucins: Signaling receptors at the intersection of inflammation and cancer. J Innate Immun 9: 281-299.

113. Aihara E, Engevik KA, Montrose MH (2017) Trefoil factor peptides and gastrointestinal function. Annu Rev Physiol 79: $357-380$

114. Dignass A, Lynch-Devaney K, Kinbdon H, Thim L, Podolsky DK (1994) Trefoil peptides promote epithelial migration through a transforming growth factor $\beta$-independent pathway. J Clin Invest 94: 376-383.

115. lizuka M, Konno S (2011) Wound healing of intestinal epithelial cells. World J Gastroenterol 17: 2161-2171.

116. Wong WM, Playford RJ, Wright NA (2000) Peptide gene expression in gastrointestinal mucosal ulceration: Or- dered sequence or redundancy? Gut 46: 286-292.

117. Peitz U, Kouznetsova I, Wex T, Gebert I, Vieth M, et al. (2004) TFF3 expression at the esophagogastric junction is increased in gasto- esophageal reflux disease (GERD). Peptides 25: 771-777.

118. Longman R, Douthwaite J, Sylvester PA, Poulsom R, Corfield AP, et al. (2000) Coordinated localization of mucins and trefoil peptides in the ulcer associated cell lineage and the gastrointestinal mucosa. Gut 47: 792-800.

119. Gum JR, Hicks JW, Toribara NW, Siddiki B, Kim YS (1994) Molecular cloning of human intestinal mucin (MUC2) cDNA. Identification of the amino terminus and overall sequence similarity to pre-pro-von Willibrand factor. J Biol Chem 269: 2440-2446.

120. van Roon AHC, Mayne GC, Wijnhoven BPL, Watson DI, Leong MP, et al. (2008) Impact of gastro-esophageal reflux on mucin mRNA expression in the esophageal mucosa. J Gastrointest Surg 12: 1331-1340.

121. Carraway KL, Theodoropoulos G, Kozloski GA, Carraway CAC (2009) Muc4/MUC4 functions and regulation in cancer. Future Oncol 5: 1631-1640.

122. Hollander D, Tarnawski A, Gergely H, Zipser RD (1984) Sucralfate protection of the gastric mucosa against ethanol- induced injury: A prostaglandin-meidated process? Scand J Gastroenterol Suppl 19: 97-102.

123. Hollander D, Tarnawski A, Krause WJ, et al. (1985) Protective effect of sucralfate against alcohol-induced gastric mucosal injury in the rat. Macroscopic, histologic, ultrastructural and functional time sequence analysis. Gastroenterology 88: 366-374.

124. Szabo S, Brown A (1987) Prevention of ethanol-induced vascular injury and gastric mucosal lesions by sucralfate and its components: Possible role of endogenous sulfhydryls. Proc Soc Exp Biol Med 185: 493-497.

125. Bianchi Porro G, Hollander D (1989) Treatment of digestive disease with sucralfate. Raven Press, New York, USA.

126. Bighley L, Giesing D (1981) Mechanism of action studies of sucralfate. In: Caspary W, Duodenal ulcer, Gastric ulcer: Sucralfate, a new treatment concept. Urban \& Schwarzenberg, Munich, 3-12.

127. Carraway KL, Ramsauer VP, Haq B, Carothers-Carraway CA (2003) Cell signaling through membrane mucins. Bioessays 25: $66-71$.

128. Cone RA (2009) Barrier properties of mucus. Adv Drug Deliv Rev 61: 75-85.

129. Pelaseyed T, Zach M, Petersson AC, Svensson F, Johansson DG, et al. (2013) Unfolding dynamics of the mucin SEA domain probed by force spectroscopy suggest that it acts as a cell-protective device. FEBS J 280: 14911501.

130. Martinez SD, Malagon IB, Garewal HS, Cui H, Fass R (2003) Non-erosive reflux disease (NERD)--acid reflux and symptom patterns. Aliment Pharmacol Ther 17: 537 545.

131. Shiovitz TM, Bain EE, McCann DJ, Skolnick P, Laughren $T$, et al. (2016) Mitigating the effects of nonadherence in clinical trials. J Clin Pharmacol 56: 1151-1164.

132. Hetzel DJ, Dent J, Reed WD, Narielvala FM, Mackinnon $M$, et al. (1988) Healing and relapse of severe peptic esophagitis after treatment with omeprazole. Gastroenterology 95: 903-912. 
133. Khan M, Santana J, Donnellan C, Preston C, Moayyedi P (2007) Medical treatments in the short term management of reflux oesophagitis. Cochrane Database Syst Rev 2: CD003244.

134. Stoker DL, Williams JG, Dewar EP (1988) The pH and concentration of bile in the oesophagus. Gut 29: A728-A279.

135. Kedika RR, Souza RF, Spechler SJ (2009) Potential anti-inflammatory effects of proton pump inhibitors: A review and discussion of the clinical implications. Dig Dis Sci 54: 2312-2317.

136. Modlin IM, Hunt RH, Malfertheiner P, Moayyedi P, Quigley EM, et al. (2009) Diagnosis and management of non-erosive reflux disease--the Vevey NERD Consensus Group. Digestion 80: 74-88.

137. Sun D, Wang X, Gai Z, Song X, Jia X, et al. (2015) Bile acids but not acidic acids induce Barrett's esophagus. Int J Clin Esp Phathol 8: 1384-1392.
138. Dulai GS, Guha S, Kahn KL, Gornbein J, Weinstein WM (2002) Preoperative prevalence of Barrett's esophagus in esophageal adenocarcinoma: A systematic review. Gastroenterology 122: 26-33.

139. Souza RF (2016) From reflux esophagitis to esophageal adenocarcinoma. Dig Dis 34: 483-490.

140. Dunbar KB, Agoston AT, Odze RD, Huo X, Pham TH, et al. (2016) Association of acute gastroesophageal reflux disease with esophageal histologic changes. JAMA 315: 2104-2112.

141. Souza RF, Bayeh L, Spechler SJ, Tambar UK, Bruick RK (2017) A new paradigm for GERD pathogenesis. Not acid injury, but cytokine- mediated inflammation driven by HIF-

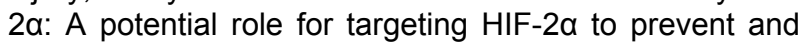
treat reflex espohagitis. Curr Opin Pharmacol 37: 93-99.

142. Yoshida N, Terao N, Nagashima R (1979) Sucralfate, a basic aluminum salt of sucrose sulfate. IV. Interaction with enzyme pepsin. Arzneim Forschi Drug Res 30: 78-80. 